\title{
Visible-Light-Induced Trifluoromethylation of Unactivated Alkenes with Tri(9-anthryl)borane as an Organophotocatalyst
}

\author{
Jisu Moon, ${ }^{\dagger}$ Yu Kyung Moon,,${ }^{\ddagger}$ Do Dam Park,,${ }^{\dagger}$ Sukyung Choi,,${ }^{\ddagger}$ \\ Youngmin You,,$*$ and Eun Jin Cho ${ }^{*}, \dagger$
}

$\dagger$ Department of Chemistry, Chung-Ang University, 84 Heukseok-ro, Dongjak-gu, Seoul 06974, Republic of Korea

$\$$ Division of Chemical Engineering and Materials Science, Ewha Womans University, Seoul 03760, Republic of Korea

E-mail: odds2@ewha.ac.kr (Y.Y.) and ejcho@ cau.ac.kr (E.J.C.)

\section{Supporting Information}

Additional Experiments

Reference 


\section{Additional Experiments}

\section{Electrochemical Characterization}

Cyclic and differential pulse voltammetry experiments were carried out using a $\mathrm{CH}$ Instruments, CHI630 B potentiostat using a three-electrode-cell assembly. A Pt wire and a Pt microdisc were used as the counter and the working electrodes, respectively. $\mathrm{An} \mathrm{Ag} / \mathrm{AgNO}_{3}$ couple was used as a pseudo reference electrode. Measurements were carried out in Ar-saturated $\mathrm{CH}_{3} \mathrm{CN}(2.0 \mathrm{~mL})$ using $0.10 \mathrm{M}$ tetra- $n$ butylammonium hexafluorophosphate $\left(\mathrm{Bu}_{4} \mathrm{NPF}_{6}\right)$ as the supporting electrolyte at scan rates of $100 \mathrm{mV} \mathrm{s}^{-1}$ (cyclic voltammetry) or $4.0 \mathrm{mV} \mathrm{s}^{-1}$ (differential pulse voltammetry). A ferrocenium/ferrocene couple was employed as the external reference. A blank scan was performed in the same range in the absence of tri(9anthryl)borane (1) in order to assess the validity of the reduction potential.

(a)

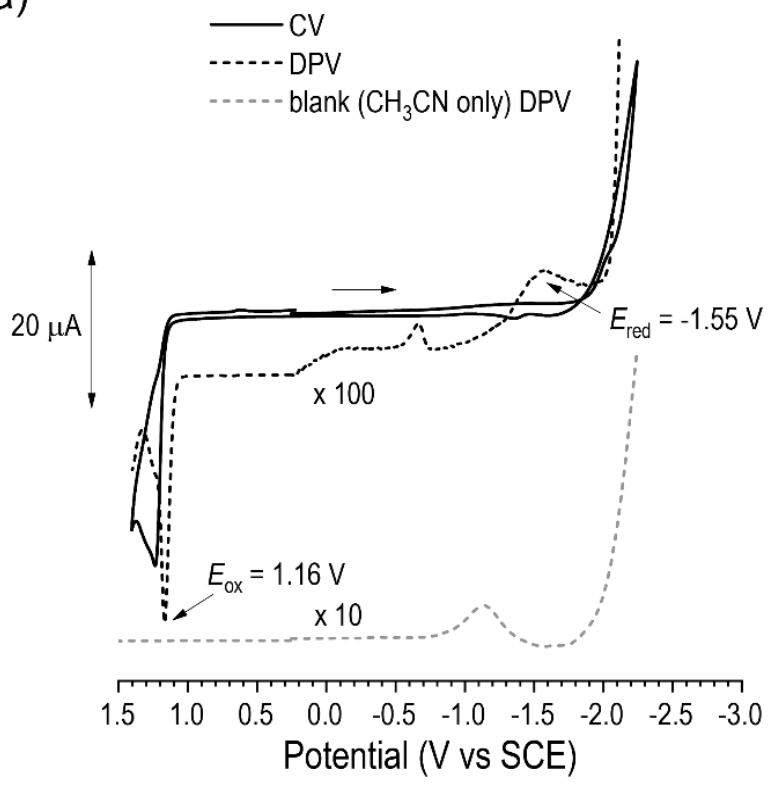

(b)
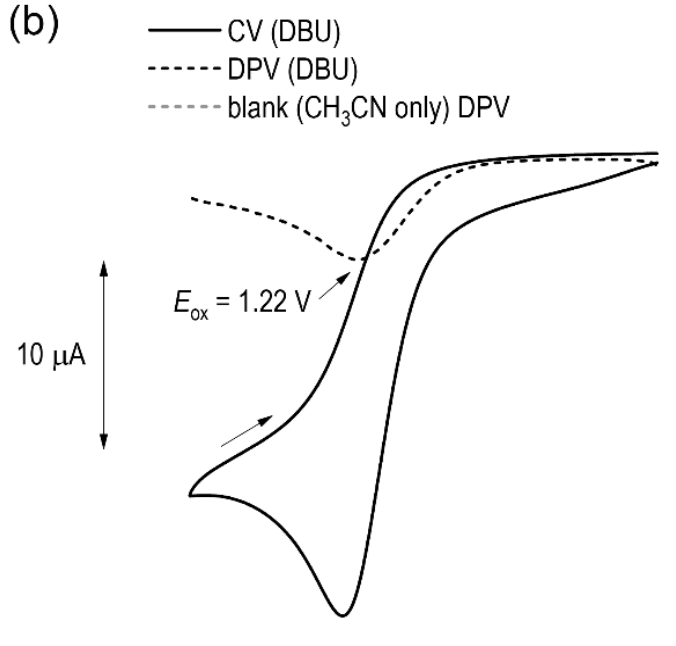

$\begin{array}{lllllllllll}2.0 & 1.8 & 1.6 & 1.4 & 1.2 & 1.0 & 0.8 & 0.6 & 0.4 & 0.2 & 0.0\end{array}$

Potential (V vs SCE)

Figure S1. (a) Cyclic (solid line) and differential pulse (dotted line) voltammograms of an Ar-saturated $\mathrm{CH}_{3} \mathrm{CN}$ solution containing $2.0 \mathrm{mM} 1$ and $0.10 \mathrm{M} \mathrm{Bu}_{4} \mathrm{NPF}_{6}$. (b) Cyclic (solid line) and differential pulse (dashed line) voltammograms for an Ar-saturated $\mathrm{CH}_{3} \mathrm{CN}$ solution containing $2.0 \mathrm{mM} \mathrm{DBU}$ and $0.10 \mathrm{M}$ $\mathrm{Bu}_{4} \mathrm{NPF}_{6}$. The dashed grey lines correspond to differential pulsed voltammograms of blank solutions (i.e., $\mathrm{CH}_{3} \mathrm{CN}$ containing $0.10 \mathrm{M} \mathrm{Bu}_{4} \mathrm{NPF}_{6}$ ). 


\section{${ }^{1}$ H NMR study of tri(9-anthryl)borane (1) with amines}

There is no Lewis acid-base interaction between $\mathbf{1}$ and amines, indicating $\mathbf{1}$ cannot function as a Lewis acid.

tri(9-anthryl)borane + DBU

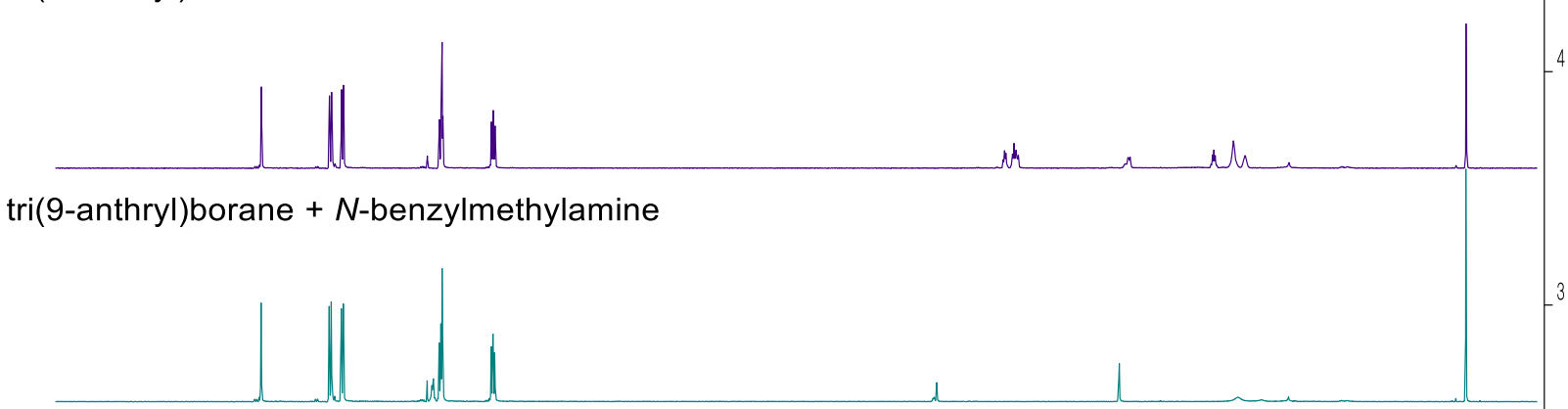

tri(9-anthryl)borane + 1-buthylamine
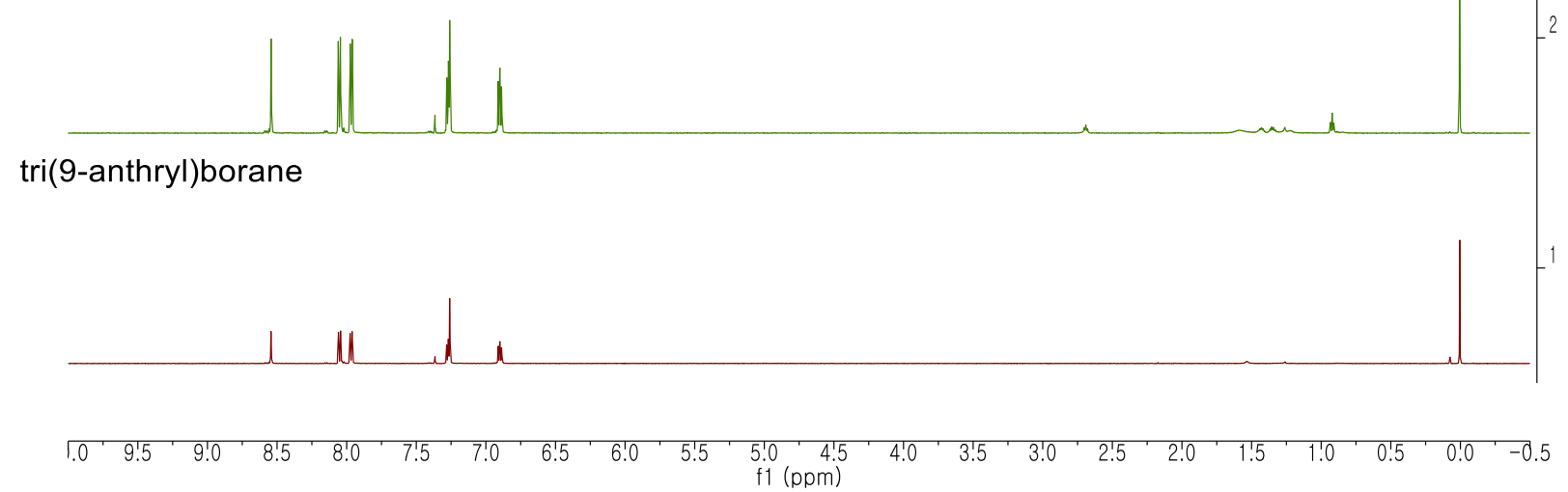

Figure S2. ${ }^{1} \mathrm{H}$ NMR spectra of $\mathbf{1}$ and amines

\section{Steady-State UV-vis Absorption Measurements}

UV-vis absorption spectra were collected on an Agilent, Cary 300 spectrophotometer at 298 K. Sample solutions were prepared prior to measurements at a concentration of $10 \mu \mathrm{M}$ in $\mathrm{CH}_{3} \mathrm{CN}$. The solution was delivered into a quartz cell (Hellma, beam path length $=1.0 \mathrm{~cm})$.

\section{Steady-State Photoluminescence Measurements}

Photoluminescence spectra were obtained using a Photon Technology International, Quanta Master 400 scanning spectrofluorometer at $298 \mathrm{~K}$. The solutions used for the steady-state UV-vis absorption studies 
were employed for the photoluminescence measurements. The solutions were deaerated by bubbling Ar prior to the measurements. A quartz cell (Hellma, beam path length $=1.0 \mathrm{~cm}$ ) was employed for solution samples. The excitation wavelength was $470 \mathrm{~nm}$. The photoluminescence spectra were recorded in the emission range 350-700 $\mathrm{nm}$. The photoluminescence excitation spectra were recorded in the range $300-500 \mathrm{~nm}$ at an emission wavelength of $545 \mathrm{~nm}$.

\section{Monitoring Photoluminescence Decay Traces}

Deaerated $\mathrm{CH}_{3} \mathrm{CN}$ solutions of $100 \mu \mathrm{M}$ sample were employed. Photoluminescence decay traces were acquired based on time-correlated single-photon-counting (TCSPC) techniques, using a PicoQuant, FluoTime 200 instrument after nanosecond pulsed laser excitation at $377 \mathrm{~nm}$ (pulse duration $=8 \mathrm{ps}$ ). Transient photon signals were collected at $\lambda_{\mathrm{obs}}=545 \mathrm{~nm}$ through an automated motorized monochromator. The photon acquisition was terminated when the accumulated photon count reached $10^{5}$. Photoluminescence decay traces were recorded with the addition of $120 \mu \mathrm{L}$ from a $1.0 \mathrm{M} \mathrm{CF}_{3} \mathrm{I}$ stock solution $\left(\mathrm{CH}_{3} \mathrm{CN}\right)$. Photoluminescence decay traces were analyzed using a monoexponential decay model embedded in an OriginLab, OriginPro 2018 software.

\section{Determination of Quantum Yields of Trifluoromethylation}

The quantum yields (QYs) for trifluoromethylation were determined by the standard ferrioxalate actinometry. A $0.0060 \mathrm{M} \mathrm{K}_{3}\left[\mathrm{Fe}\left(\mathrm{C}_{2} \mathrm{O}_{4}\right)_{3}\right]$ solution served as the chemical actinometer. $1.0 \mathrm{~mL}$ of the $\mathrm{K}_{3}\left[\mathrm{Fe}\left(\mathrm{C}_{2} \mathrm{O}_{4}\right)_{3}\right]$ solution was transferred to a sealed tube with a diameter of $1.5 \mathrm{~cm}$, and the solution was photoirradiated with blue LEDs for $20 \mathrm{~s}$. Then the same volumes of $1 \mathrm{wt} \%$ 1,10-phenanthroline (aq) and a sodium acetate buffer ( $4.09 \mathrm{~g} \mathrm{CH}_{3} \mathrm{COONa}$ dissolved in $18 \mathrm{~mL}$ of $0.5 \mathrm{M} \mathrm{H}_{2} \mathrm{SO}_{4}$ and $32 \mathrm{~mL}$ of distilled water) were added and stored under dark for $1 \mathrm{~h}$. The absorbance change at $510 \mathrm{~nm}$ was recorded. Inserting the value to eq 1 returned the light intensity $\left(I_{0}\right)$ value of $4.7 \times 10^{-8}$ einstein s${ }^{-1}$ :

$$
I_{0}\left(\text { einstein } \mathrm{s}^{-1}\right)=(\Delta A b s(510 \mathrm{~nm}) \times V) /\left(\Phi \times 11050 \mathrm{M}^{-1} \mathrm{~cm}^{-1} \times \Delta t\right)
$$

In eq $1, \Delta A b s(510 \mathrm{~nm}), V, \Phi$, and $\Delta t$ are the absorbance change at $510 \mathrm{~nm}$, volume (L), the quantum yield (1.1) of the ferrioxalate actinometer, ${ }^{S I}$ and photoirradiation time (s), respectively. A $2.0 \mathrm{~mL} \mathrm{CH}_{3} \mathrm{CN}$ solution containing $0.40 \mathrm{mmol} 1$-dodecene, $0.5 \mathrm{~mol} \% \mathrm{1}, 0.8 \mathrm{mmol} \mathrm{DBU}$, and $1.2 \mathrm{mmol} \mathrm{CF}_{3} \mathrm{I}$ was photoirradiated under the identical condition for $40 \mathrm{~min}$. The trifluoromethylated product was quantitated by ${ }^{19} \mathrm{~F}$ NMR spectroscopy using $\alpha, \alpha, \alpha$-trifluorotoluene as an internal standard, and inserted into eq 2 : 


$$
Q Y=\frac{\text { [product] } \times V}{I_{0} \times \Delta t}
$$

In eq 2, [product] is the molar concentration of the trifluoromethylated, $\Delta t(\mathrm{~s})$ is the photoirradiated time, $V$ is the volume of the solution (L), and $I_{0}$ are the light intensity obtained by eq 1 (einstein $\mathrm{s}^{-1}$ ).

Scheme S1. Reaction of 1-Dodecyne

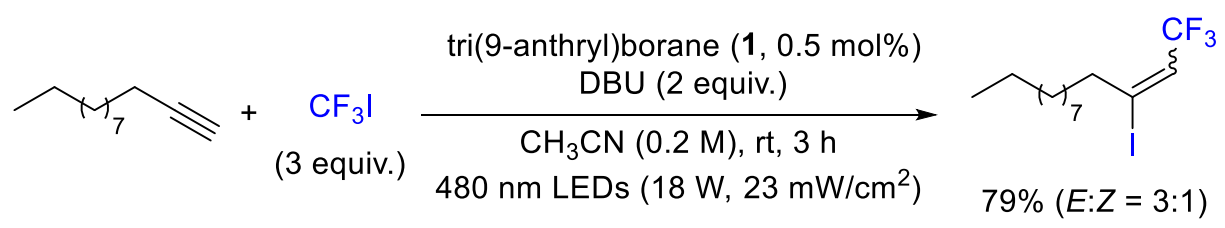

Table S1. Reactions of 1-Dodecene under Photocatalytic Conditions

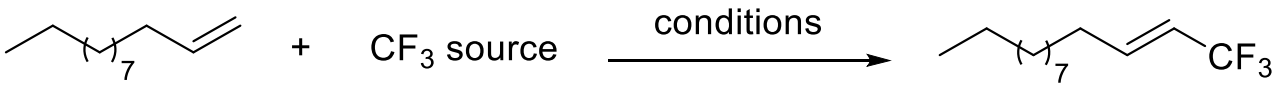

\begin{tabular}{|c|c|c|c|c|c|c|}
\hline & $\begin{array}{c}\mathbf{C F}_{3} \\
\text { source }\end{array}$ & photocatalyst & $\begin{array}{c}\text { Reaction } \\
\text { time }\end{array}$ & Solvent & Light source & yield \\
\hline $\mathrm{Cho}^{\mathrm{S} 2}$ & $\mathrm{CF}_{3} \mathrm{I}$ & $\begin{array}{c}\mathrm{Ru}(\mathrm{phen})_{3} \mathrm{Cl}_{2} \\
(0.1 \mathrm{~mol} \%)\end{array}$ & $2 \mathrm{~h}$ & $\mathrm{CH}_{3} \mathrm{CN}$ & $\begin{array}{c}\mathrm{CFL} \\
(14 \mathrm{~W})\end{array}$ & $96 \%$ \\
\hline $\begin{array}{c}\text { Fukuzumi, Cho, and } \\
\text { You }^{\mathrm{s} 3}\end{array}$ & $\mathrm{CF}_{3} \mathrm{I}$ & $\begin{array}{c}\mathrm{Pt}(\mathrm{ppy}) \mathrm{acac} \\
(1 \mathrm{~mol} \%)\end{array}$ & $5 \mathrm{~h}$ & $\mathrm{CH}_{3} \mathrm{CN}$ & $\begin{array}{c}\text { Blue LEDs } \\
(7 \mathrm{~W})\end{array}$ & $97 \%$ \\
\hline Scaiano $^{\mathrm{S4}}$ & $\mathrm{Togni}$ 's & $\begin{array}{c}\text { methylene blue } \\
(2 \mathrm{~mol} \%)\end{array}$ & $3 \mathrm{~h}$ & $\mathrm{DMF}$ & White LEDs & $\begin{array}{c}67 \% \\
(\text { alkane })\end{array}$ \\
\hline this work & $\mathrm{CF}_{3} \mathrm{I}$ & $\begin{array}{c}\text { tri(9-anthryl }) \text { borane } \\
(0.5 \mathrm{~mol} \%)\end{array}$ & $3 \mathrm{~h}$ & $\mathrm{CH}_{3} \mathrm{CN}$ & $\begin{array}{c}480 \mathrm{~nm} \mathrm{LEDs} \\
(18 \mathrm{~W})\end{array}$ & $95 \%$ \\
\hline
\end{tabular}




\section{Reference}

S1. Kuhn, H. J.; Braslavsky S. E.; Schmidt, R. Chemical actinometry. Pure. Appl. Chem. 2004, 76, $2105-$ 2146.

S2. Iqbal, N.; Choi, S.; Kim, E.; Cho, E. J. Trifluoromethylation of Alkenes by Visible Light Photoredox Catalysis. J. Org. Chem. 2012, 77, 11383-11387.

S3. Choi, W. J.; Choi, S.; Ohkubo, K.; Fukuzumi, S.; Cho, E. J.; You, Y. Mechanisms and applications of cyclometalated Pt(II) complexes in photoredox catalytic trifluoromethylation. Chem. Sci. 2015, 6, 14541464.

S4. Pitre, S. P.; McTiernan, C. D.; Ismaili, H.; Scaiano, J. C. Metal-Free Photocatalytic Radical Trifluoromethylation Utilizing Methylene Blue and Visible Light Irradiation. ACS Catal. 2014, 4, 25302535. 


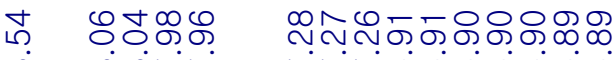

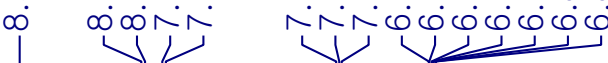
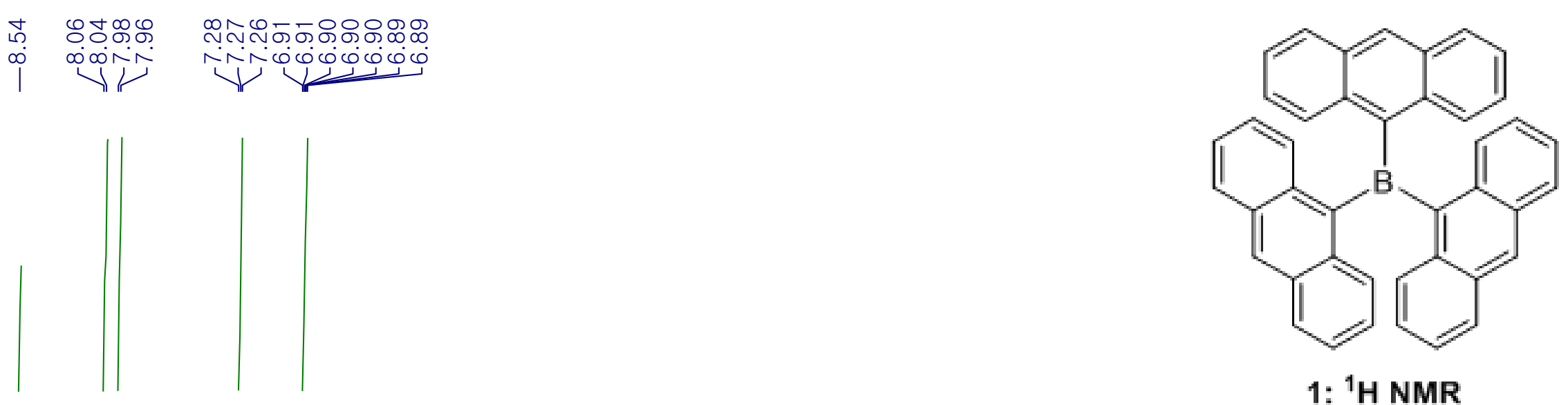

$-15$

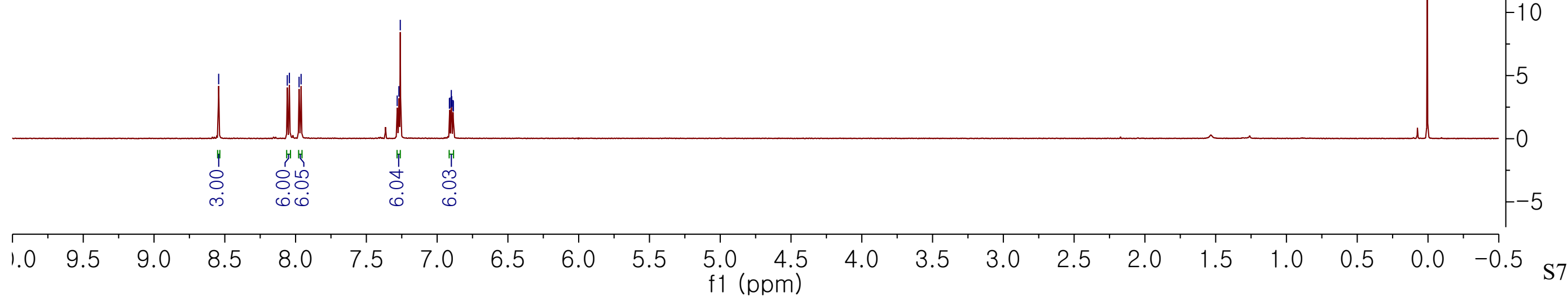




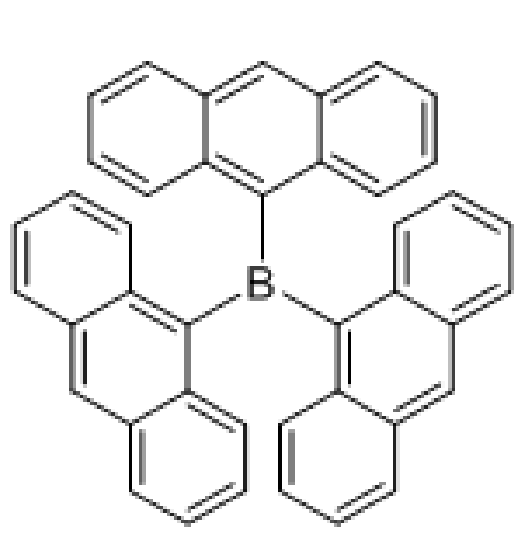

1: ${ }^{13} \mathrm{C}$ NMR

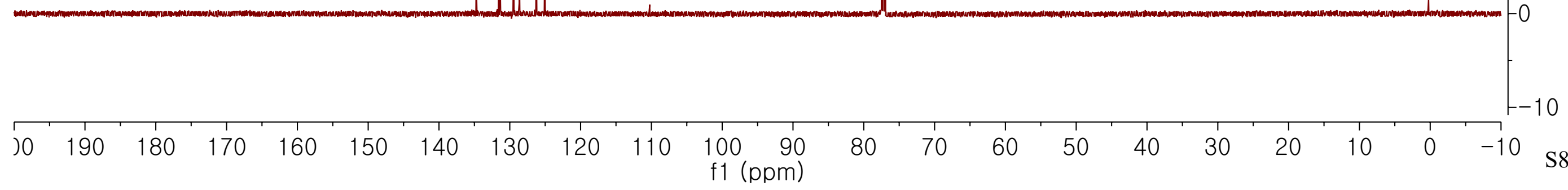




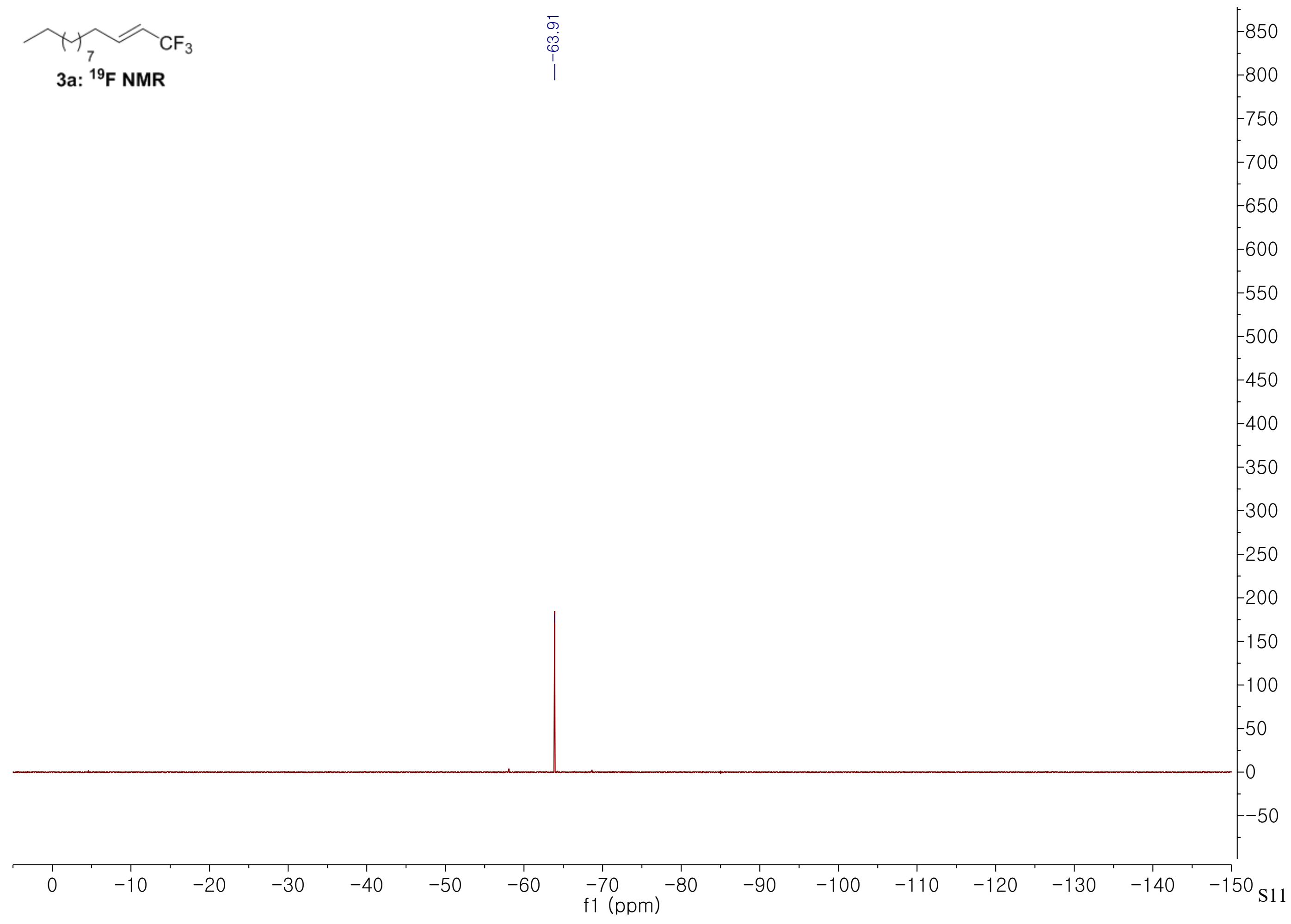




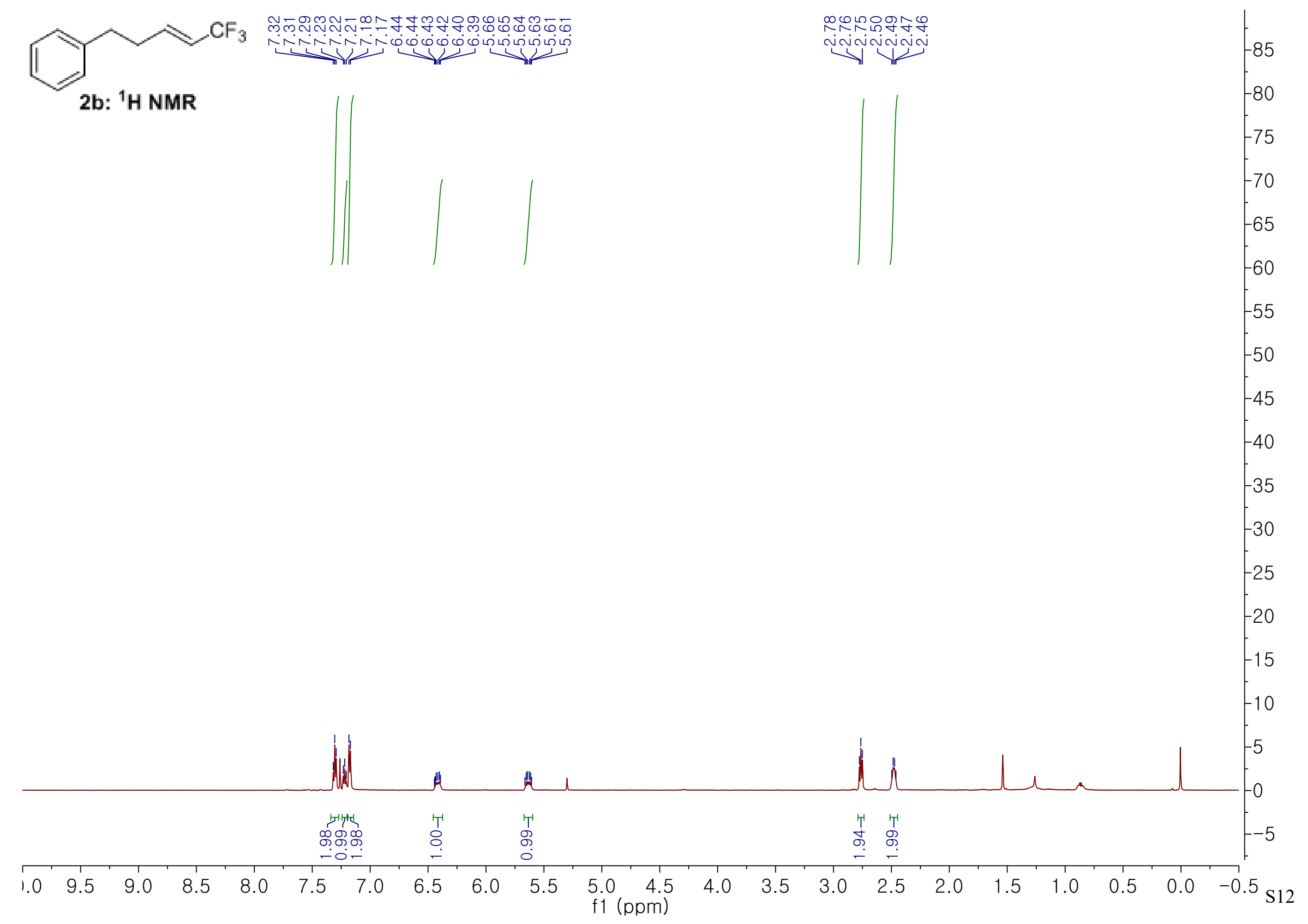




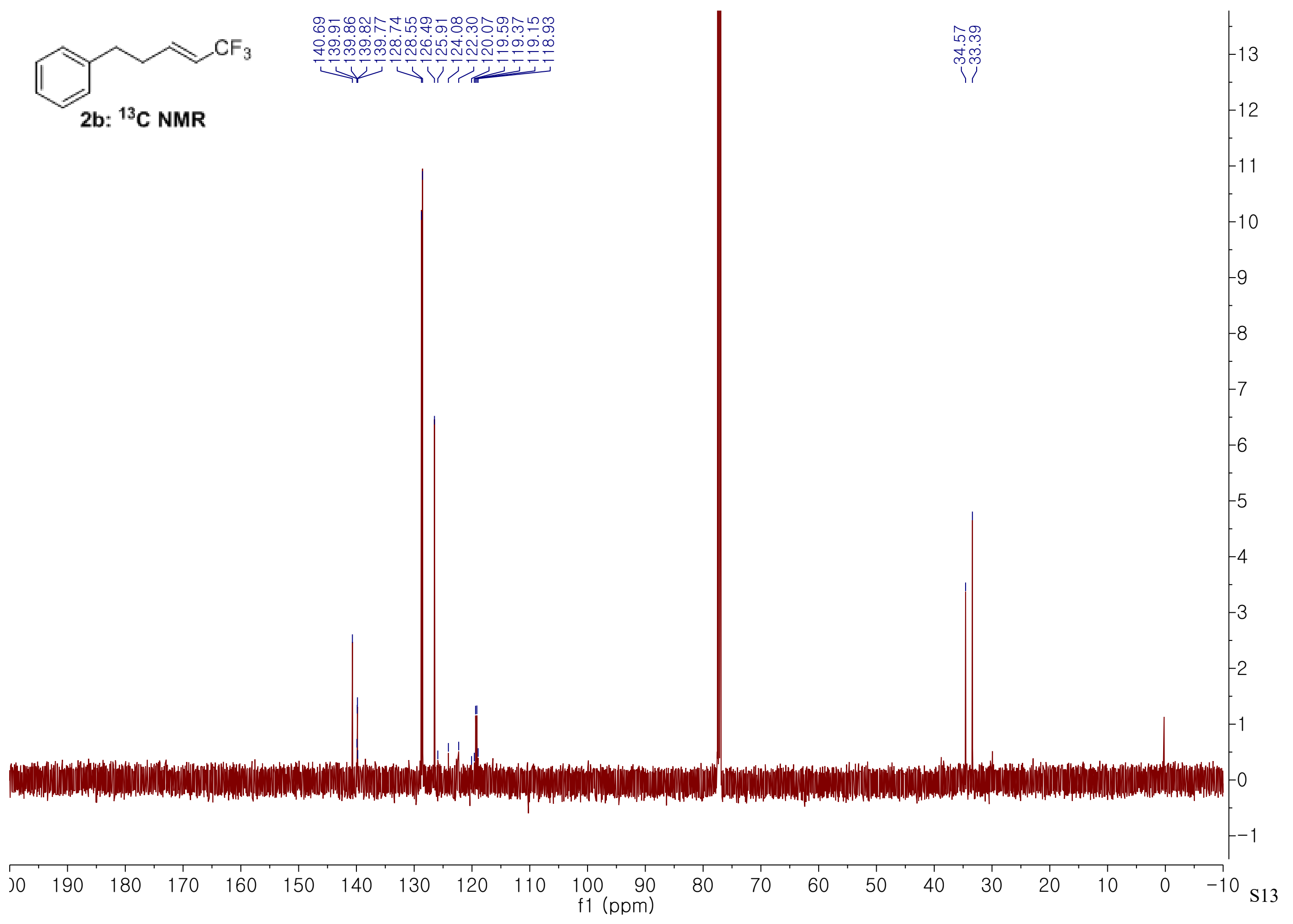


3b: ${ }^{19} \mathrm{~F}$ NMR

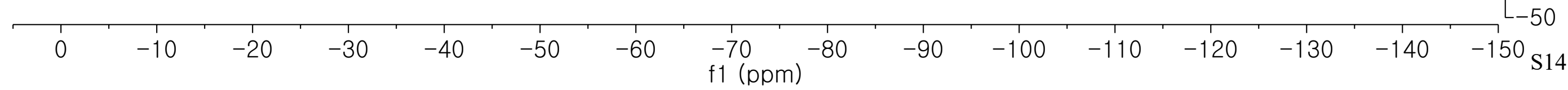



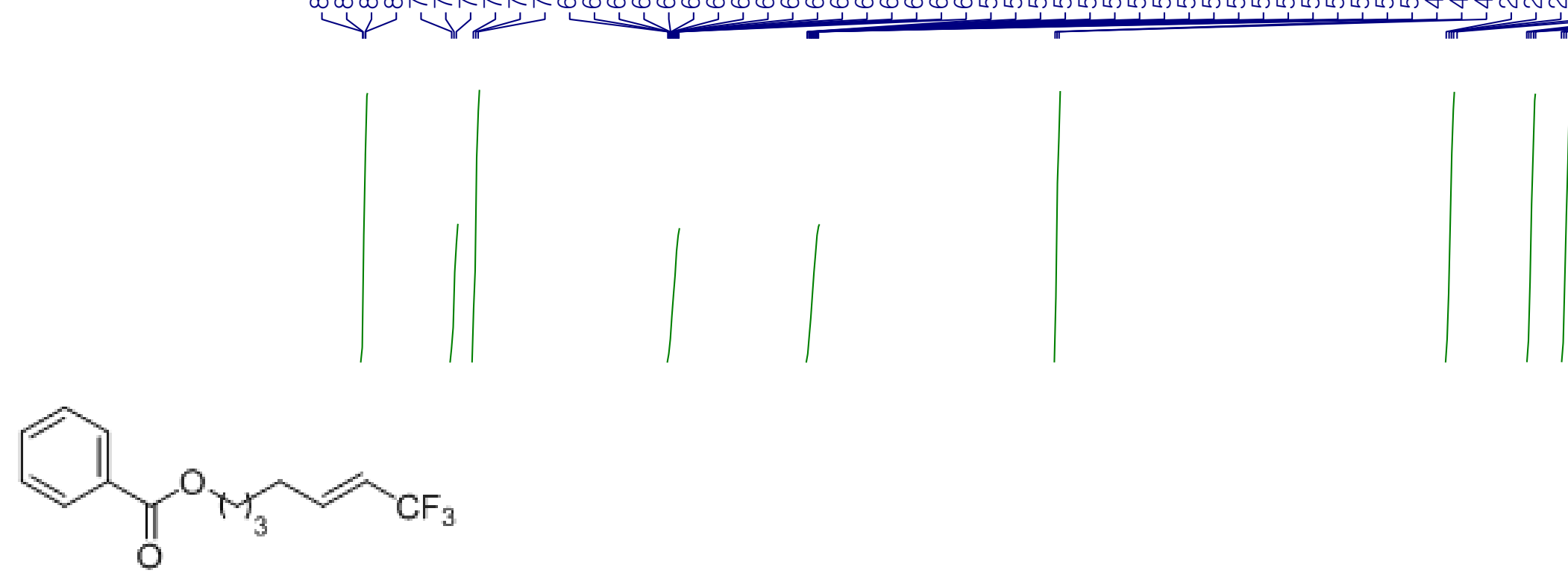

3c: ${ }^{1} \mathrm{H}$ NMR

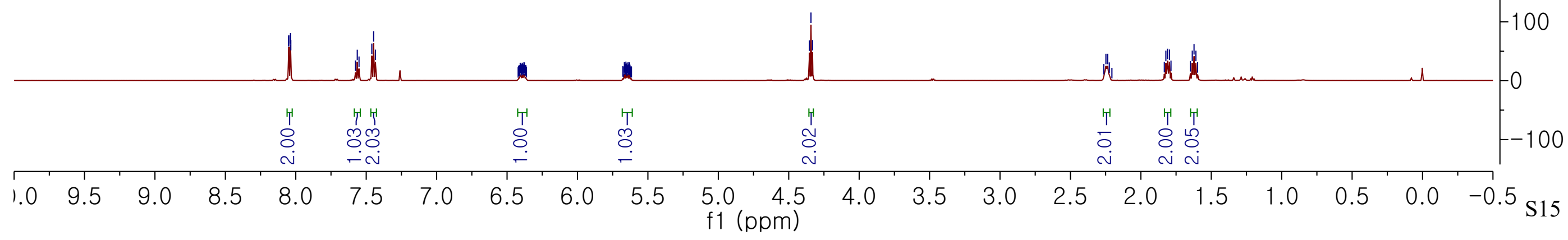




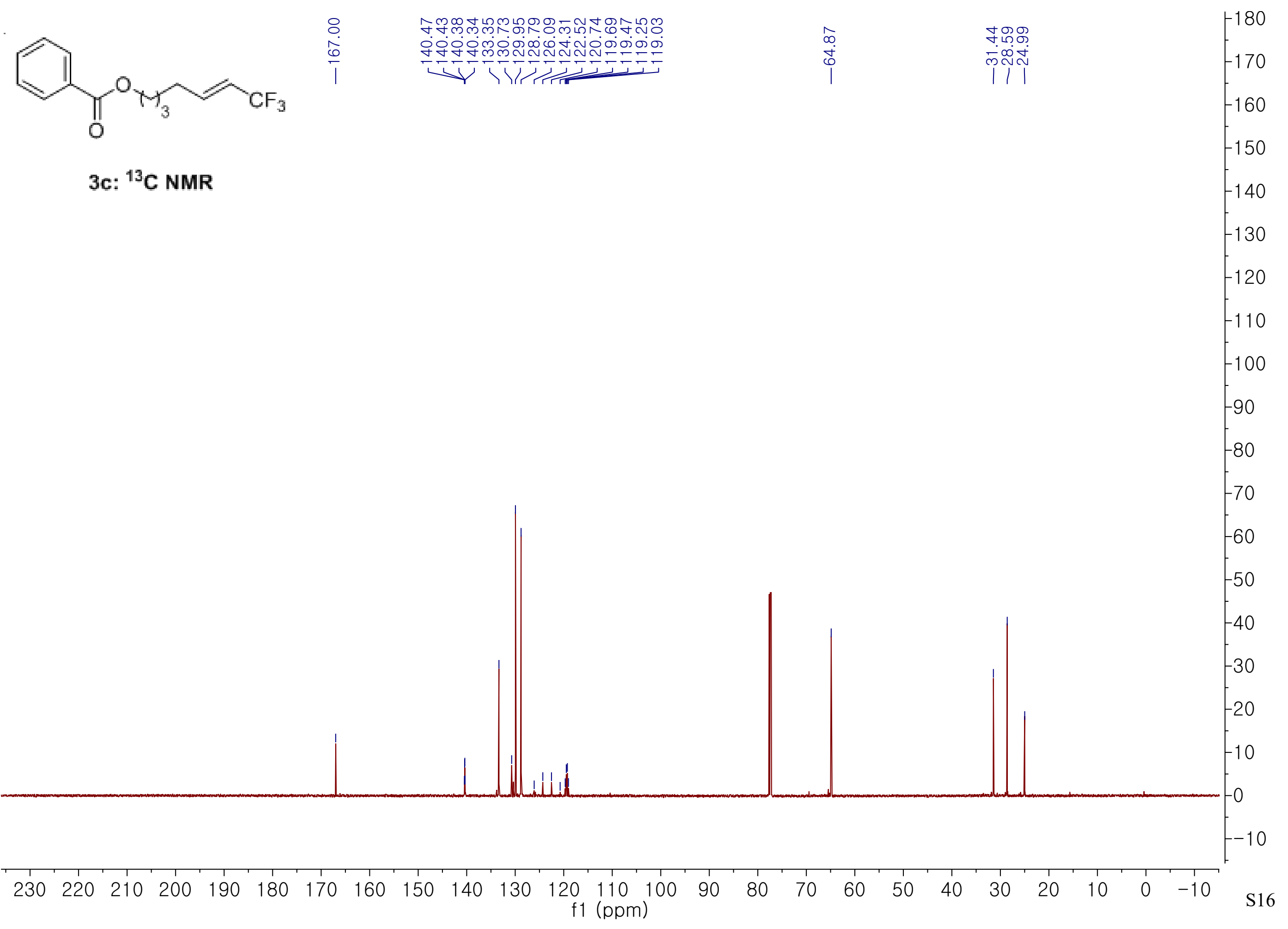




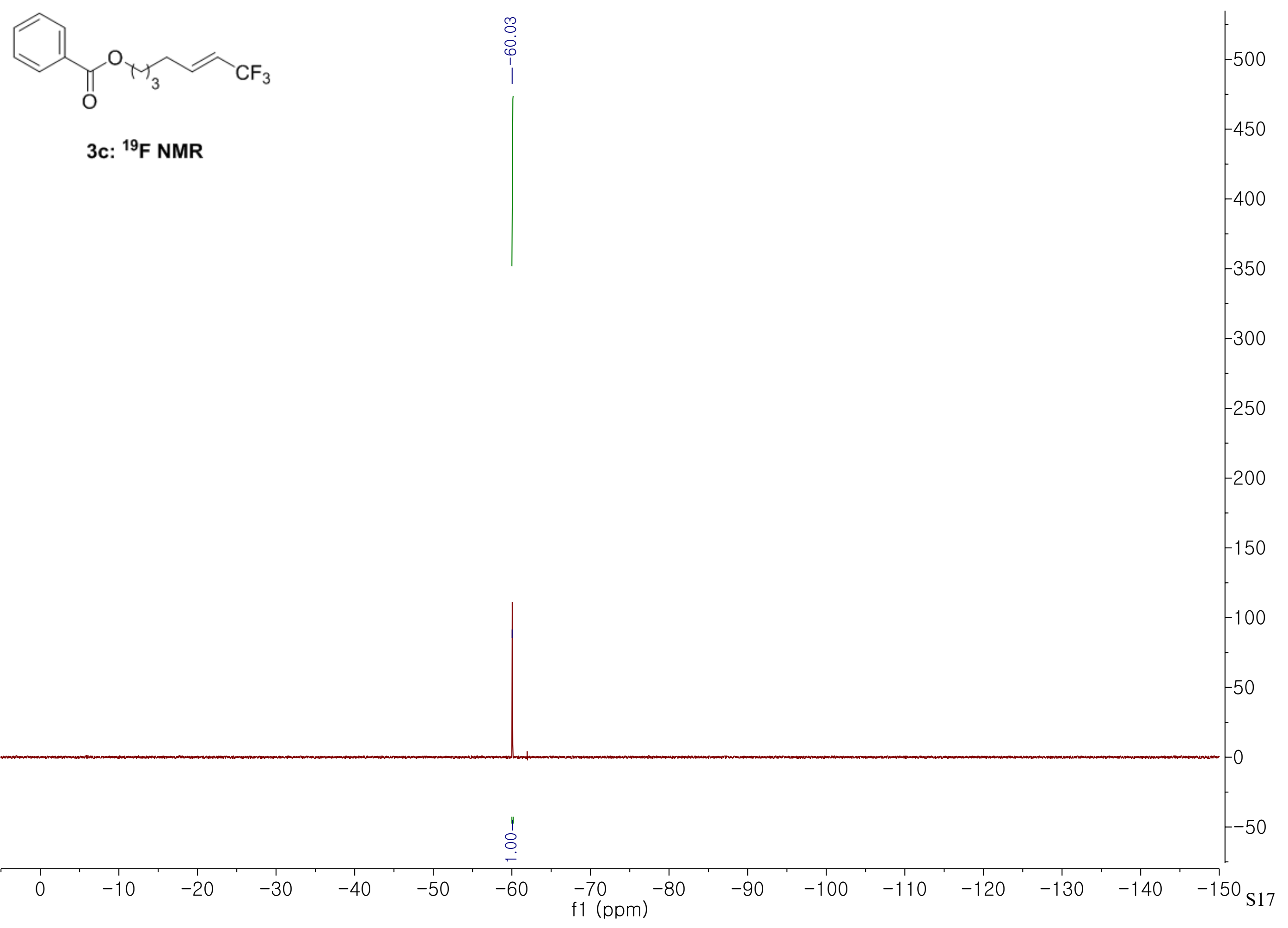




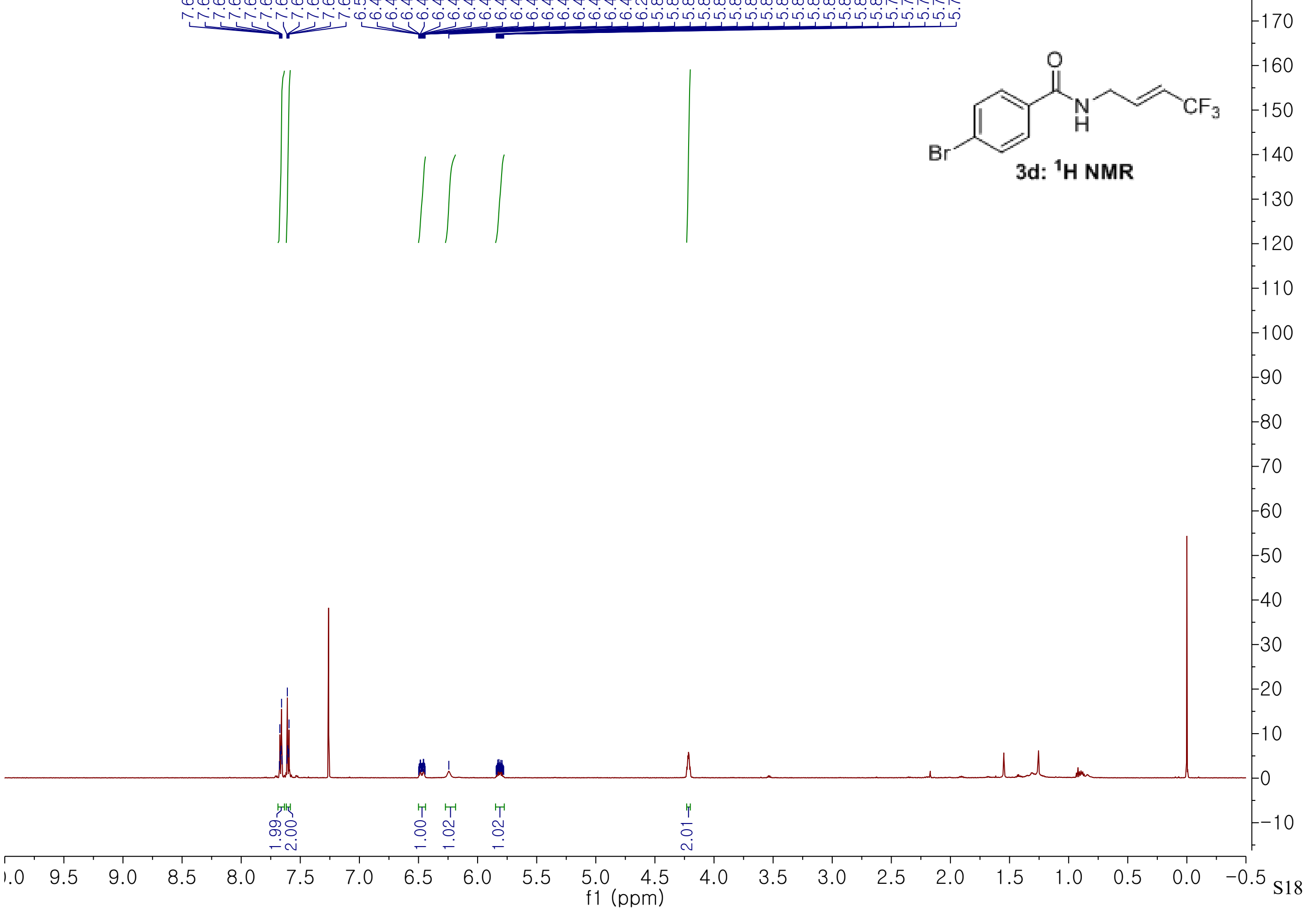




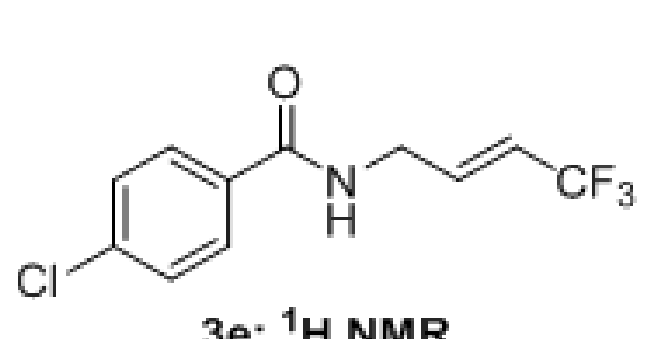

3e: ${ }^{1} \mathrm{H}$ NMR

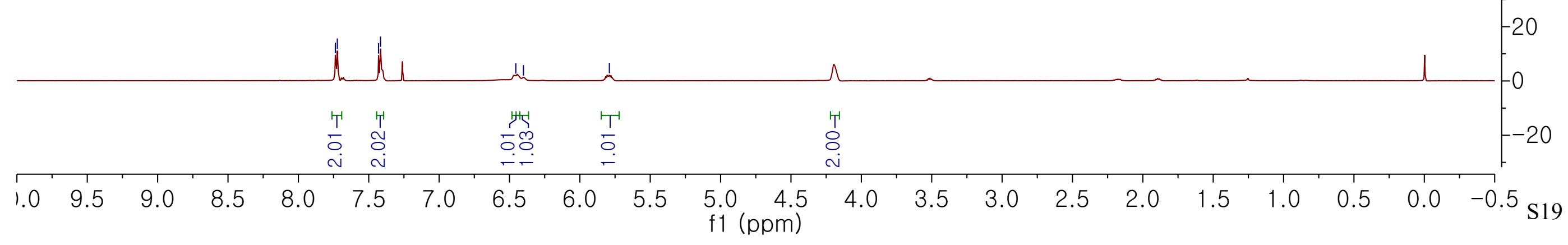




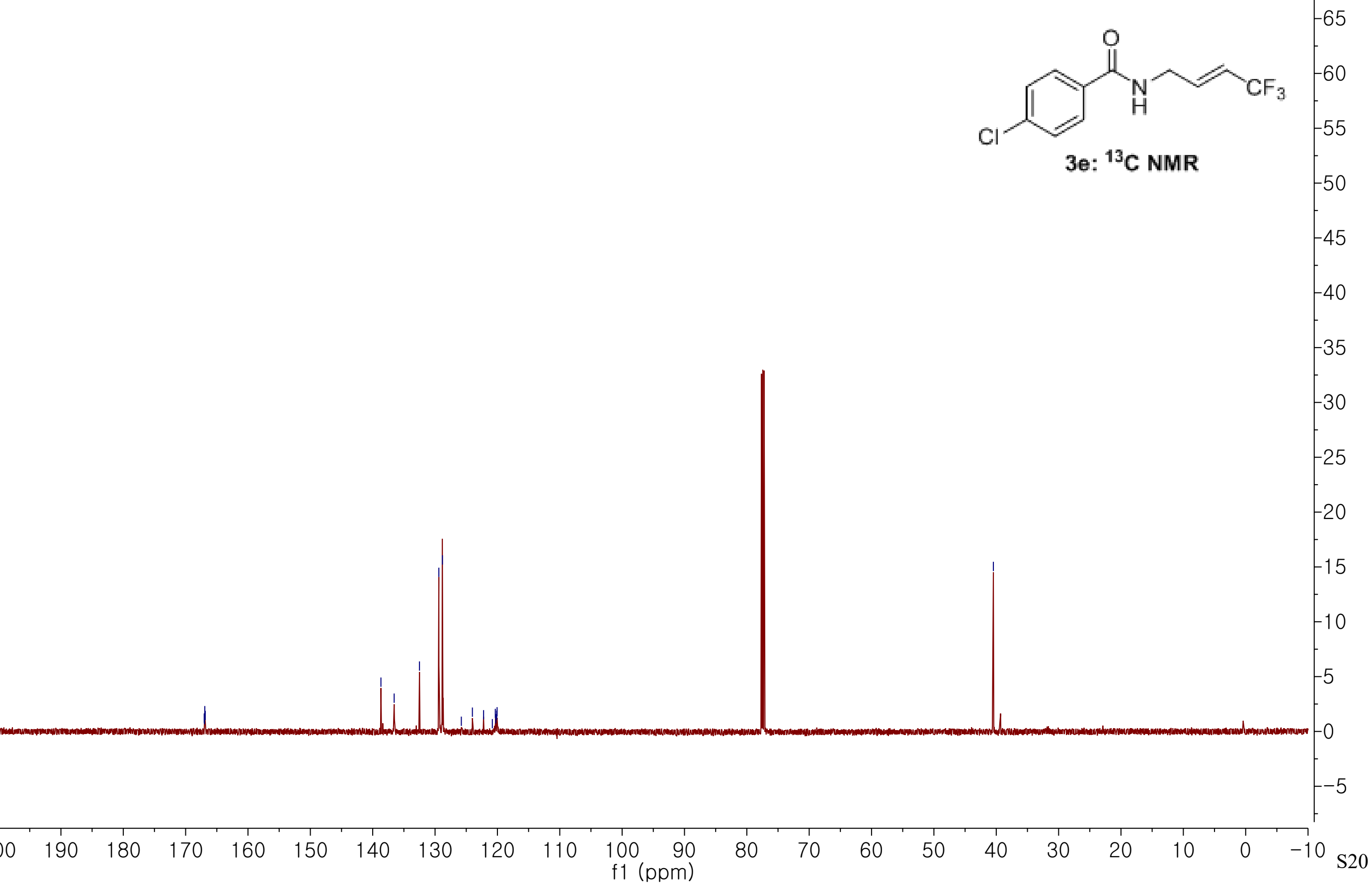




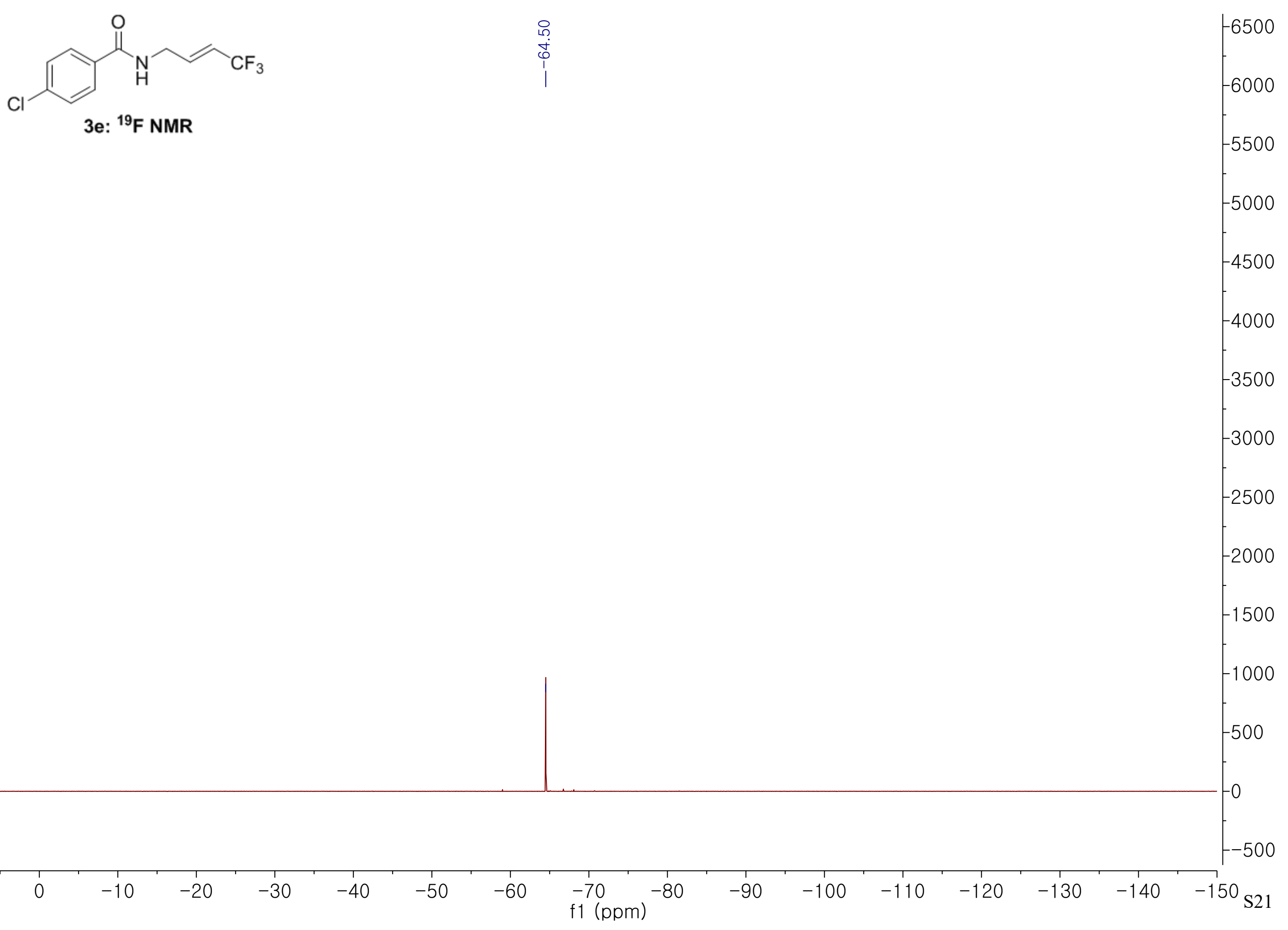



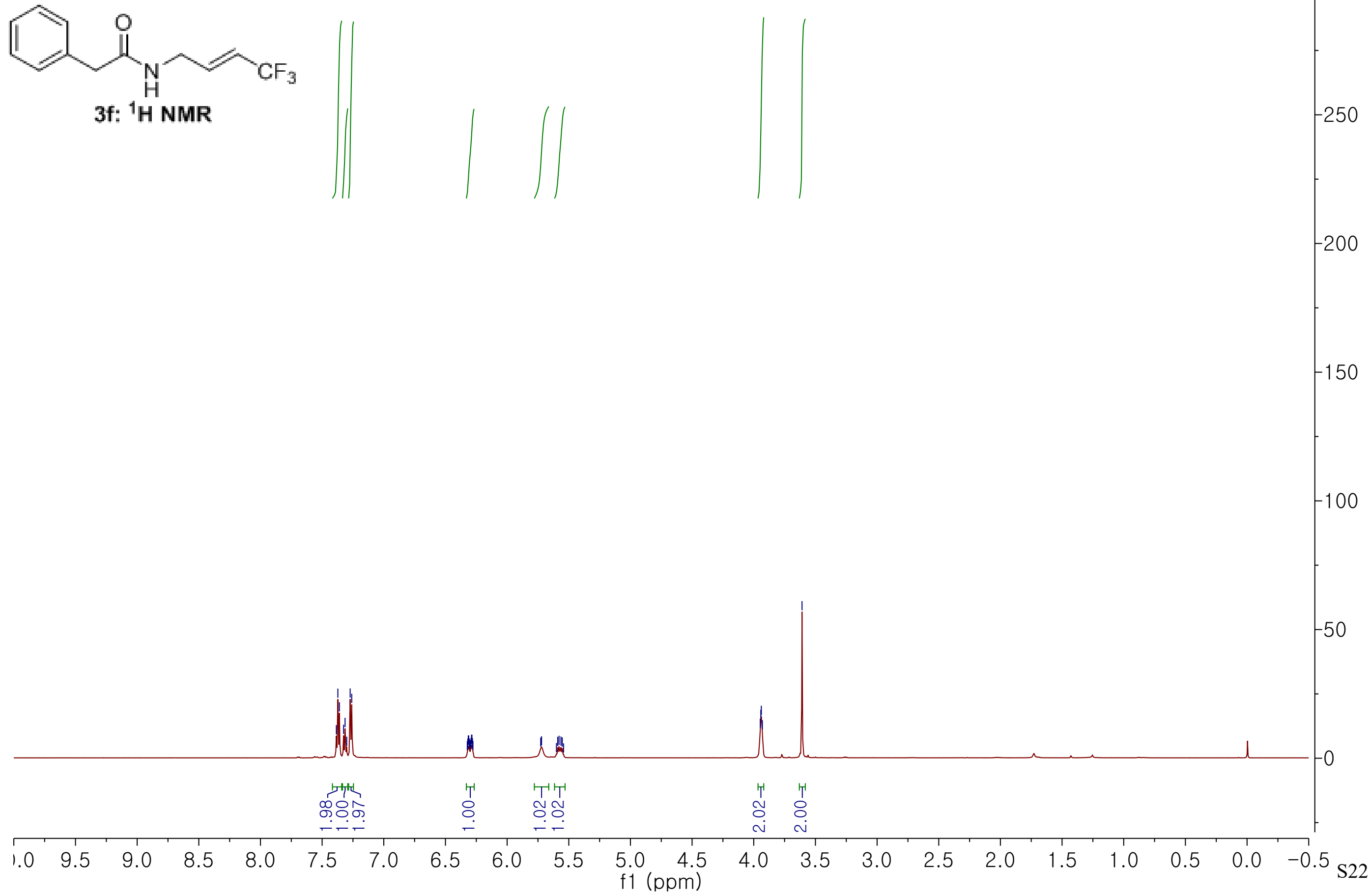


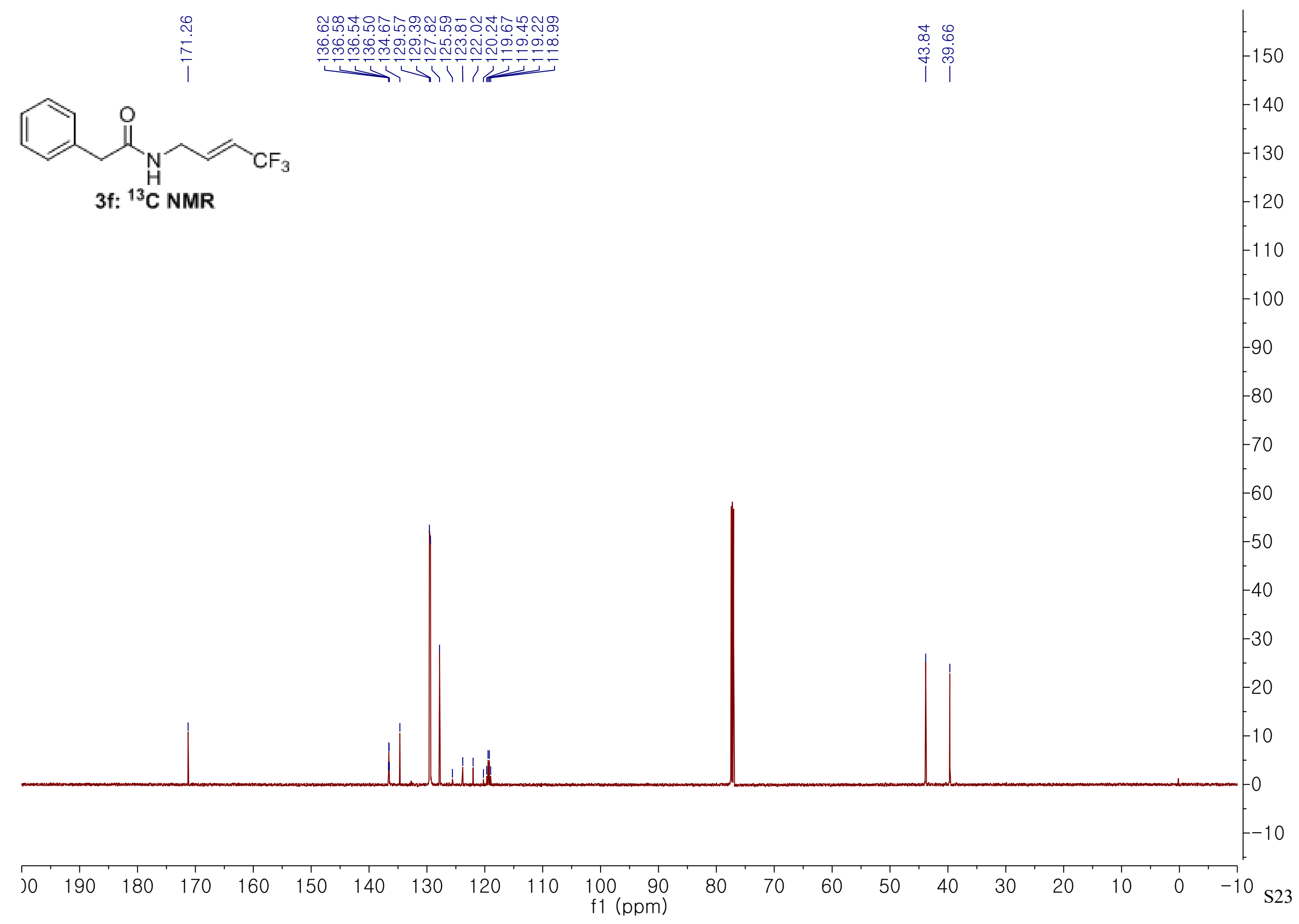


$\mathrm{CH}_{4}^{\mathrm{O}} \mathrm{C}_{\mathrm{H}}^{\mathrm{O}} \mathrm{CF}_{3}$

3g: ${ }^{1} \mathrm{H}$ NMR
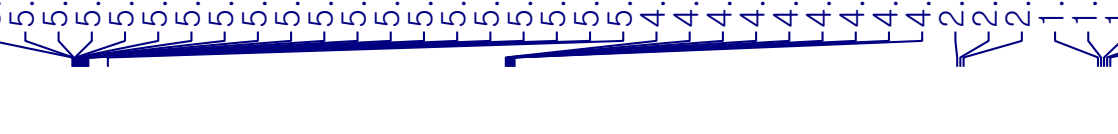

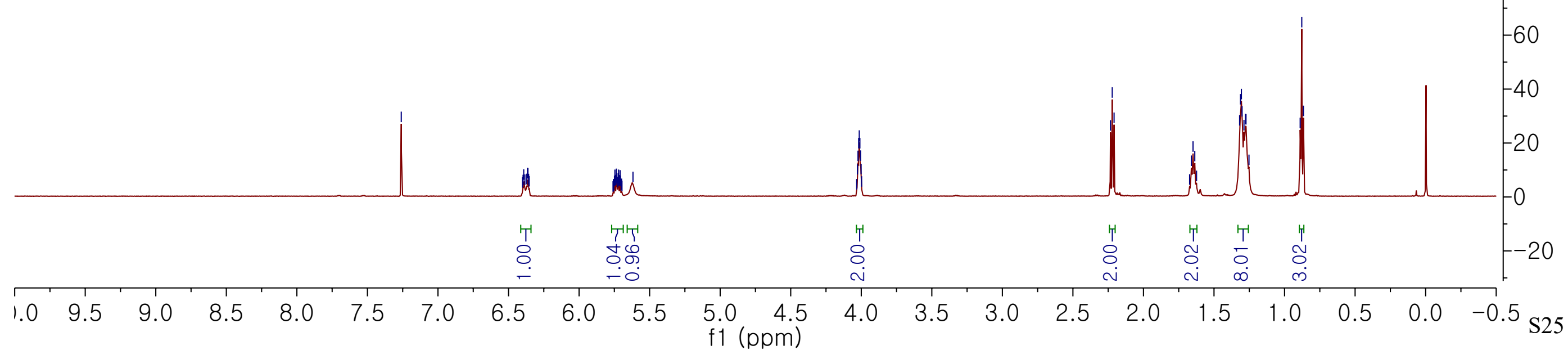




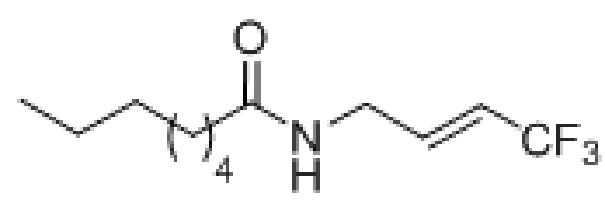

3g: ${ }^{13} \mathrm{C}$ NMR $190 \quad 180$

$170 \quad 160$

150

140

130

120

110

$\begin{array}{lr}100 & 90 \\ \mathrm{f} 1 & (\mathrm{ppm})\end{array}$

80

$\begin{array}{llll}70 & 60 & 50 & 40\end{array}$

30

20

10 


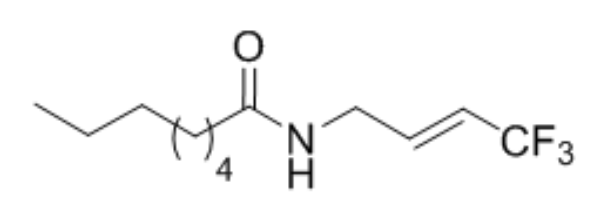

$3 g:{ }^{19} F$ NMR

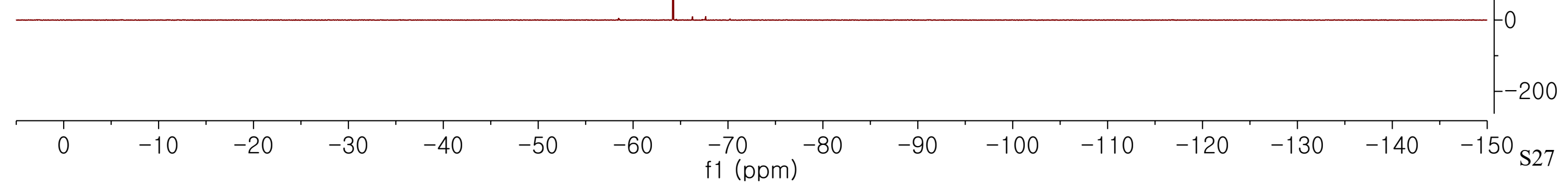




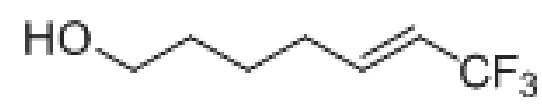

3h: ${ }^{1}$ H NMR
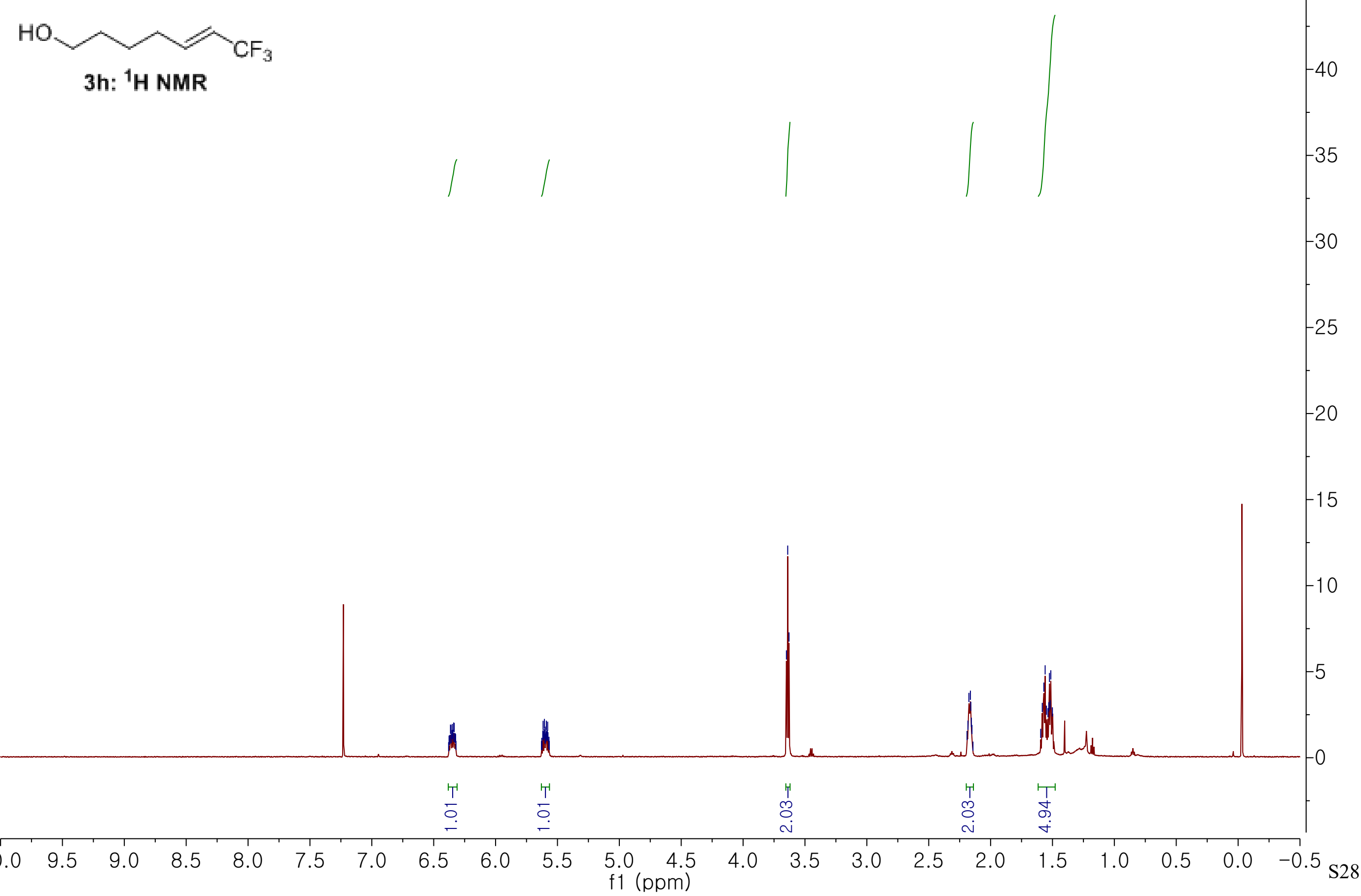


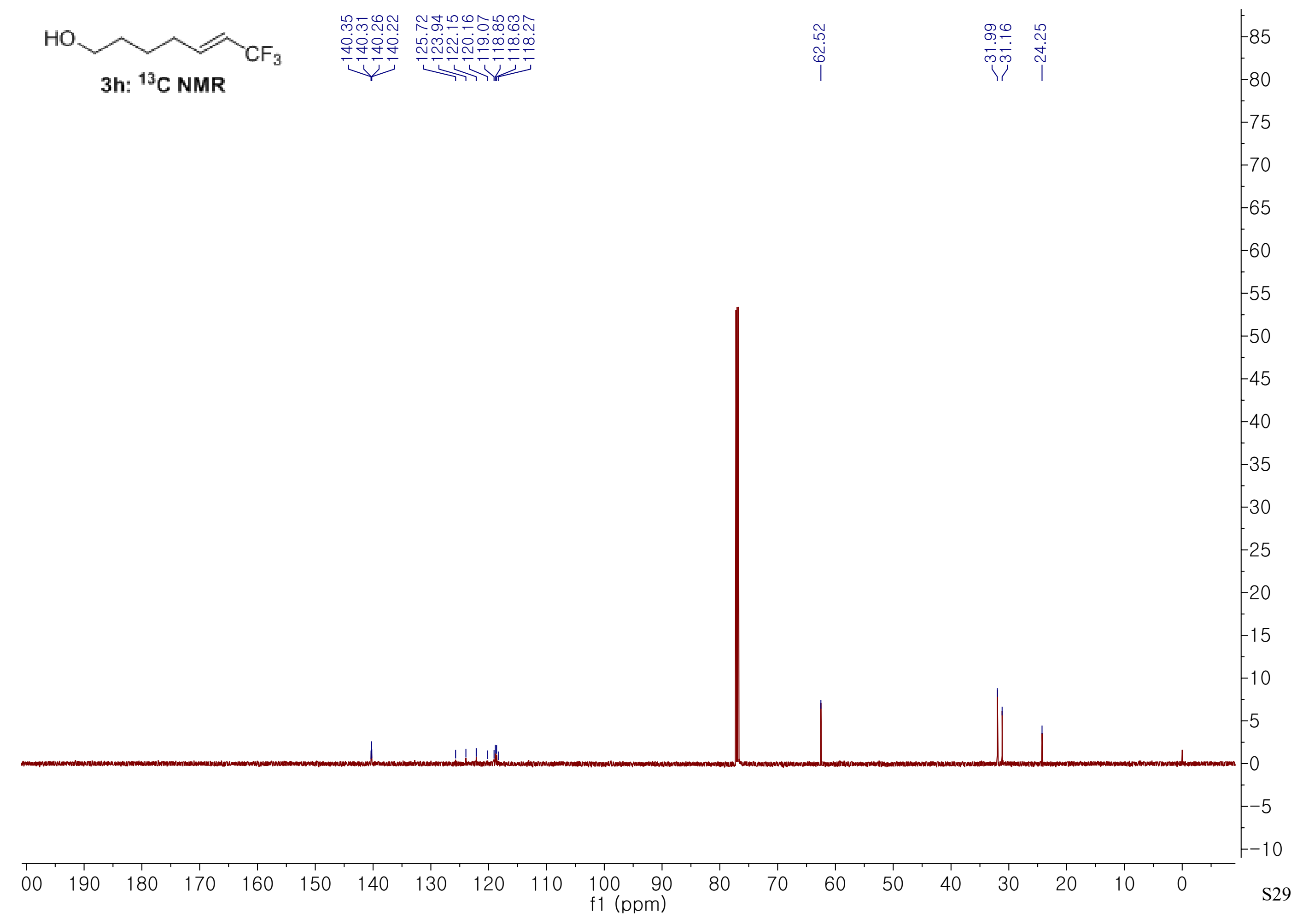


$\mathrm{CO} \mathrm{CF}_{3}$

3h: ${ }^{19} \mathrm{~F}$ NMR

\begin{tabular}{|c|c|c|c|c|c|c|c|c|c|c|c|c|c|c|}
\hline 0 & -10 & -20 & -30 & -40 & -50 & -60 & $\begin{array}{l}-70 \\
\mathrm{f1}(\mathrm{ppm})\end{array}$ & -90 & -100 & -110 & -120 & -130 & -140 & $-150 \mathrm{~S} 30$ \\
\hline
\end{tabular}




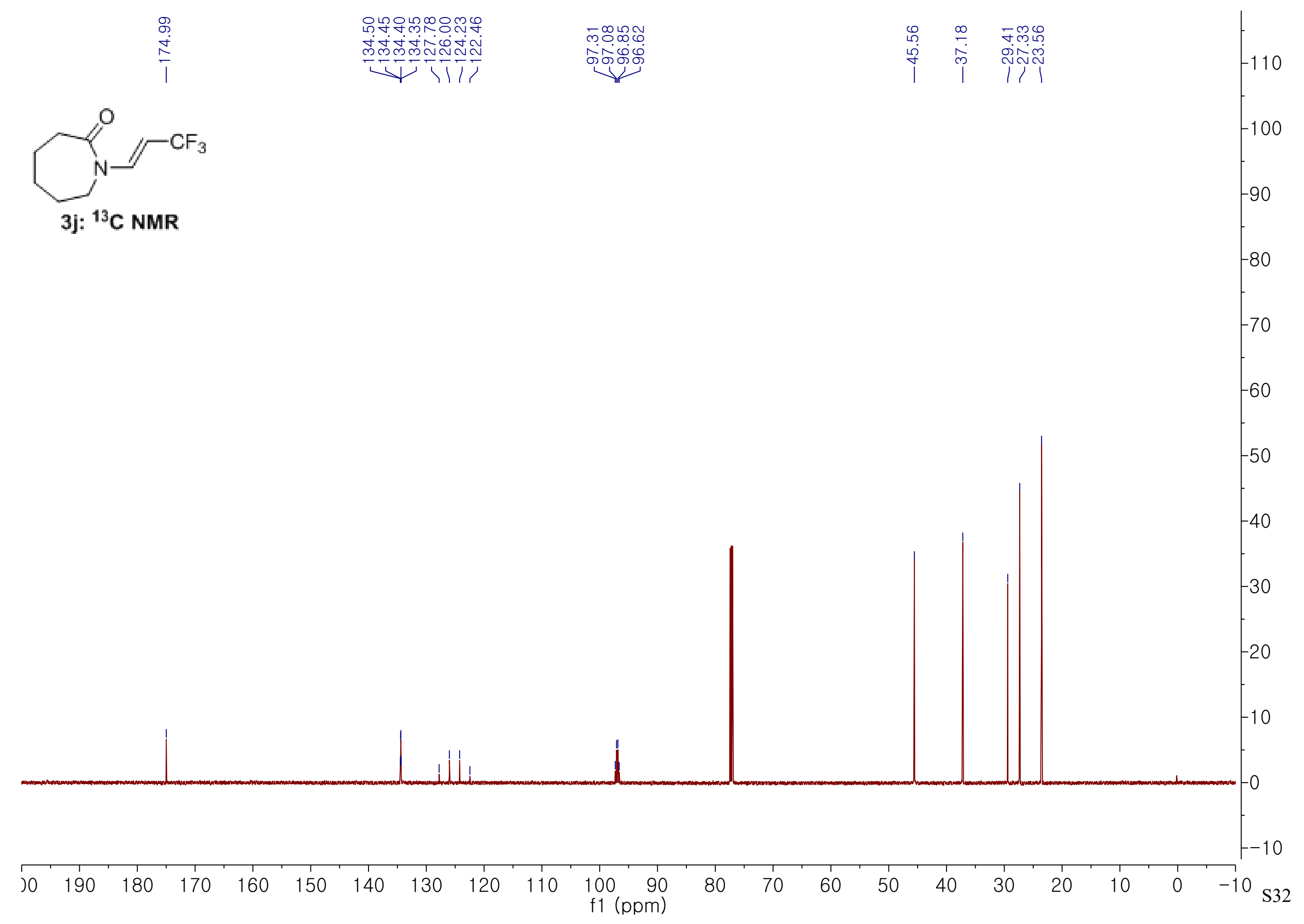




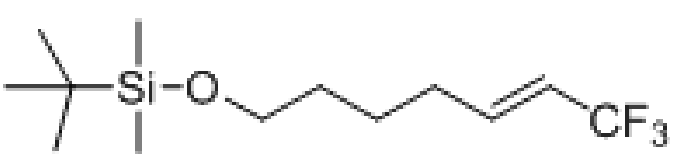

3k: ${ }^{1} \mathrm{H}$ NMR

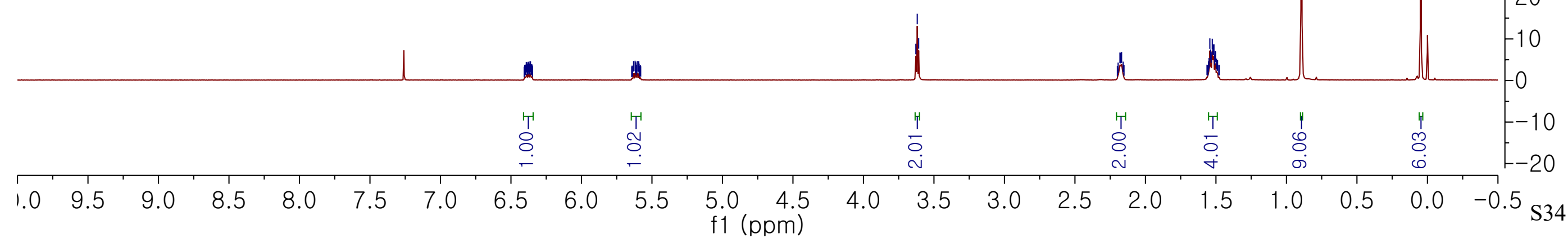




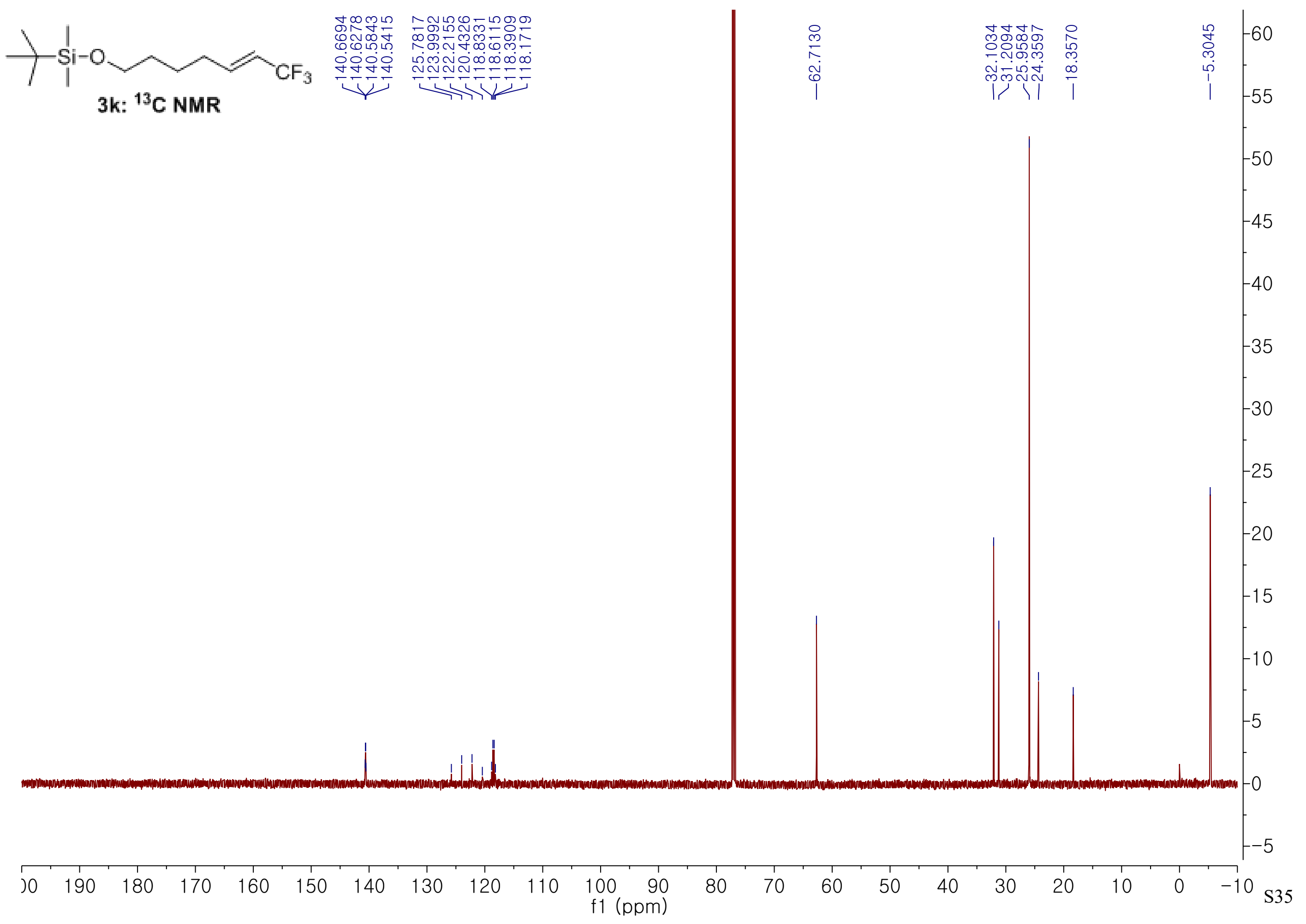




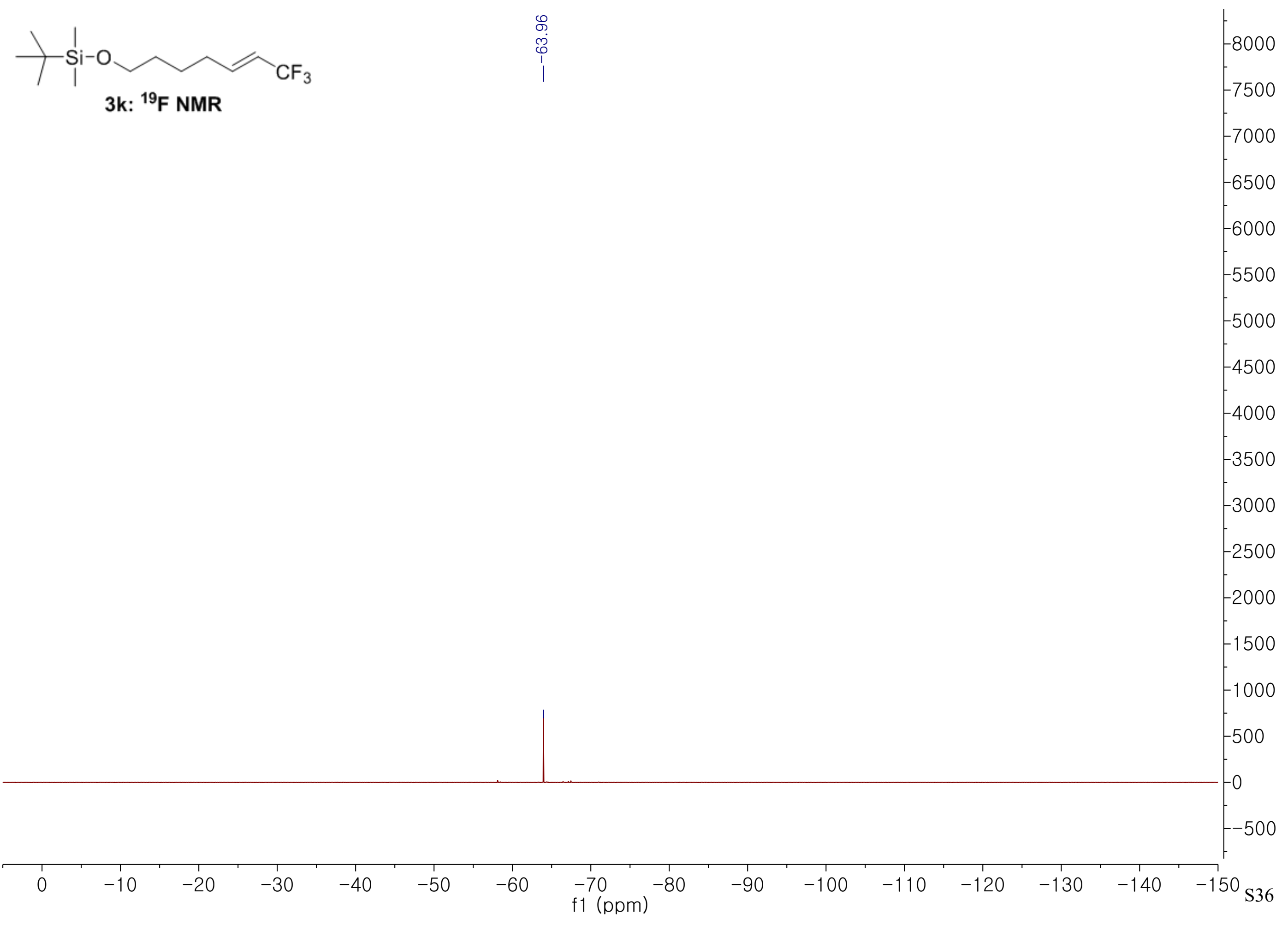



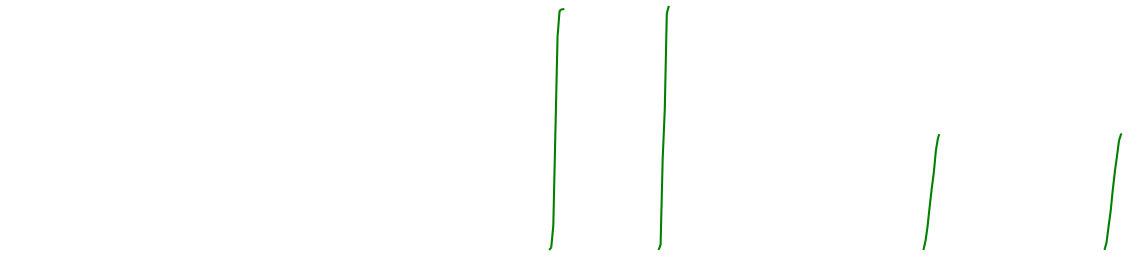

Me

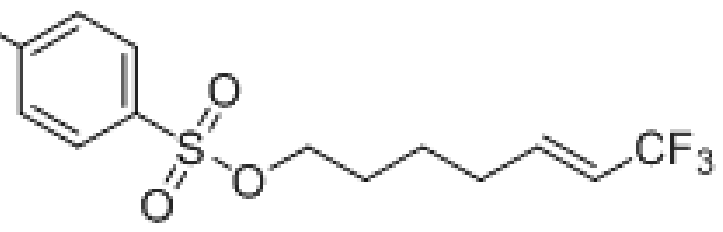

3I: ${ }^{1} \mathrm{H}$ NMR

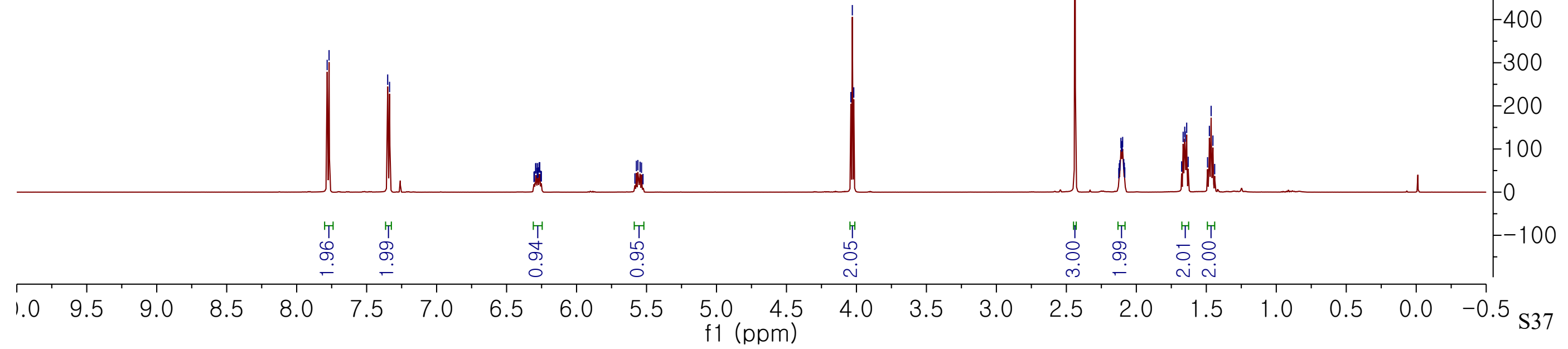


$\mathrm{Me}$<smiles>O=S(=O)(OCCCCC=CC(F)(F)F)c1ccccc1</smiles>

3I: ${ }^{13} \mathrm{C}$ NMR

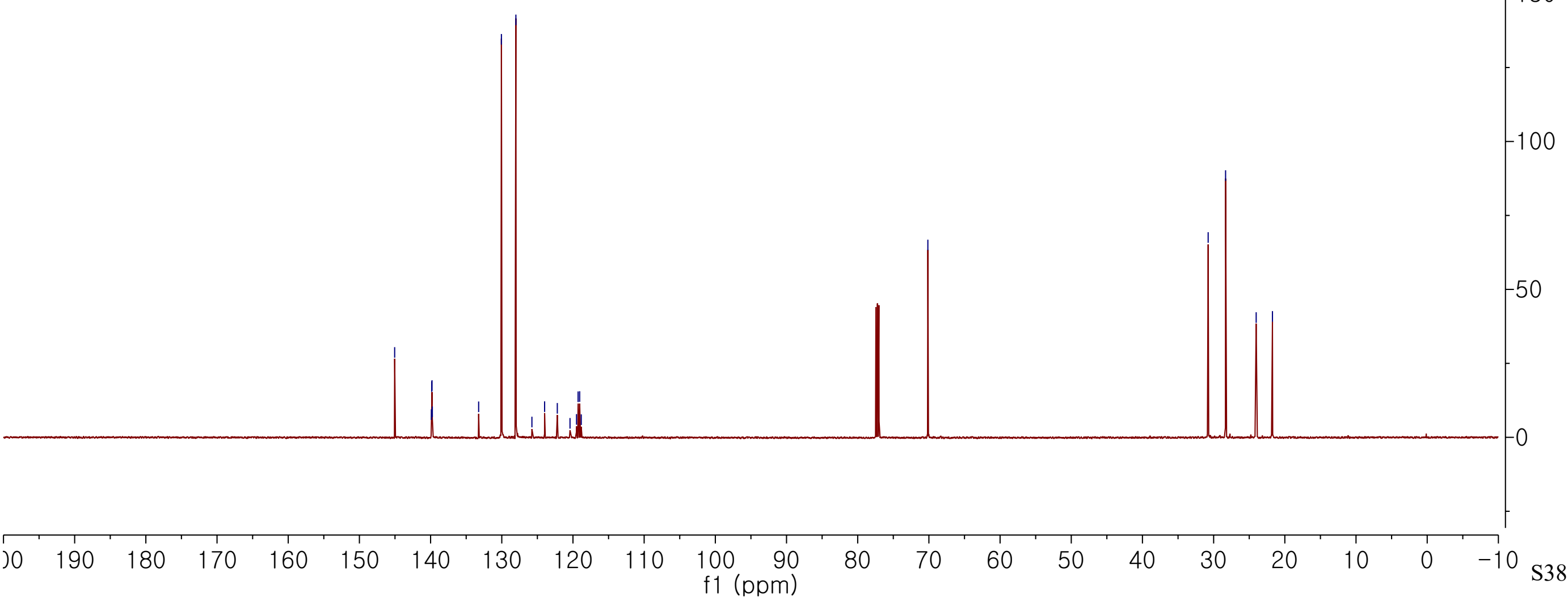




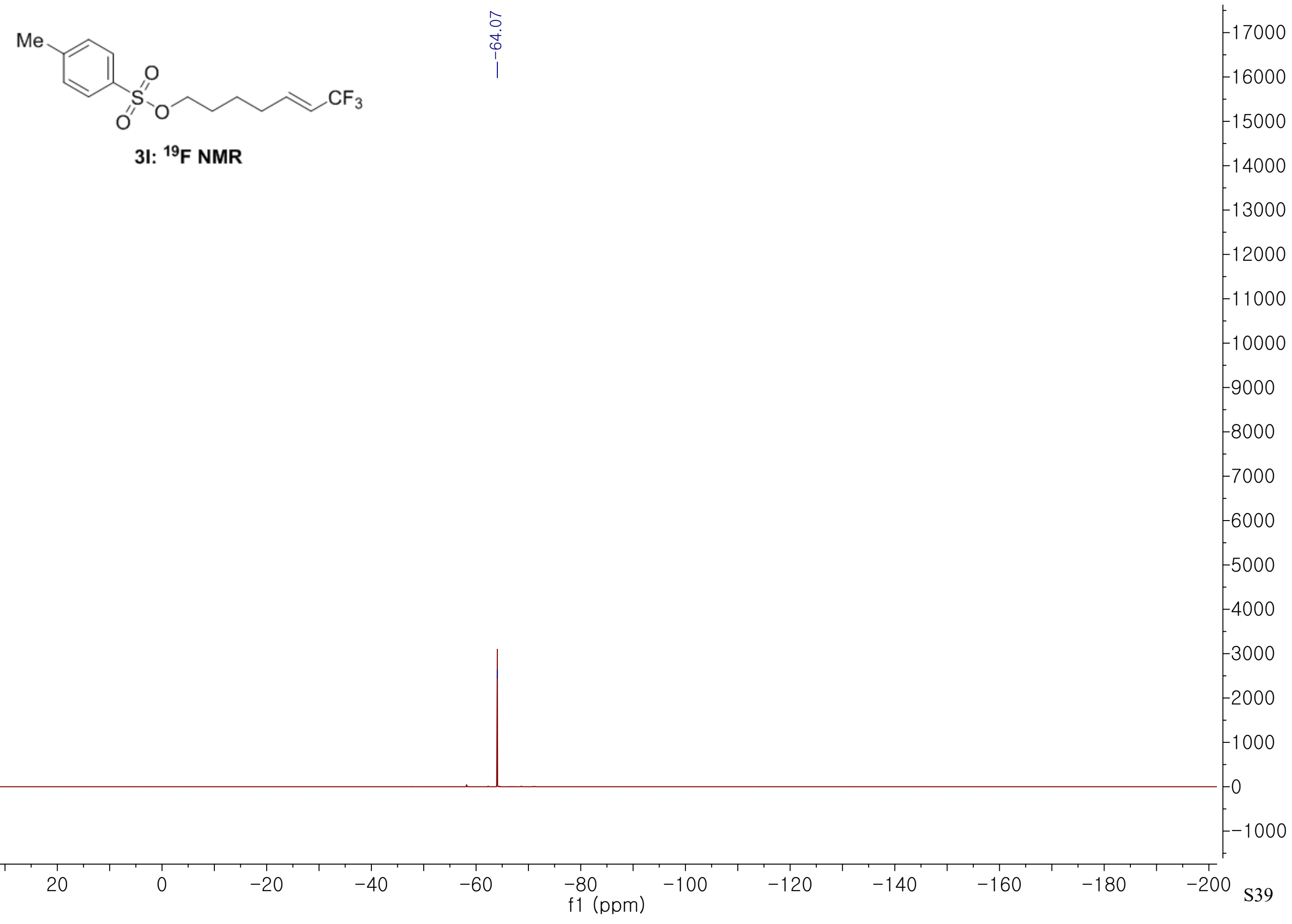


$3 \mathrm{~m}:{ }^{1} \mathrm{H}$ NMR $(E: Z=1.6: 1)$

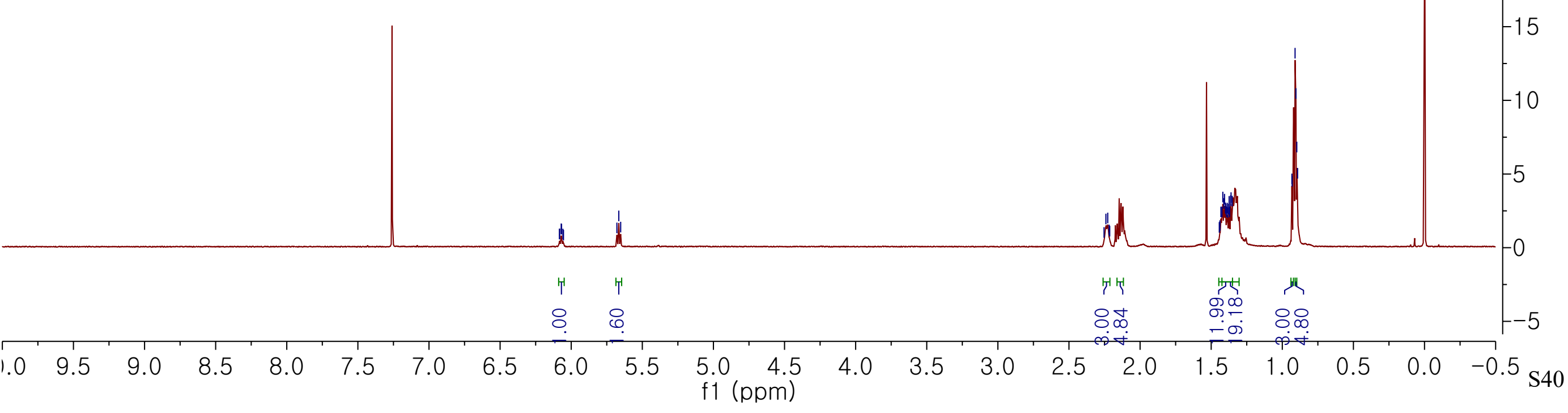


4a: ${ }^{1}$ H NMR 


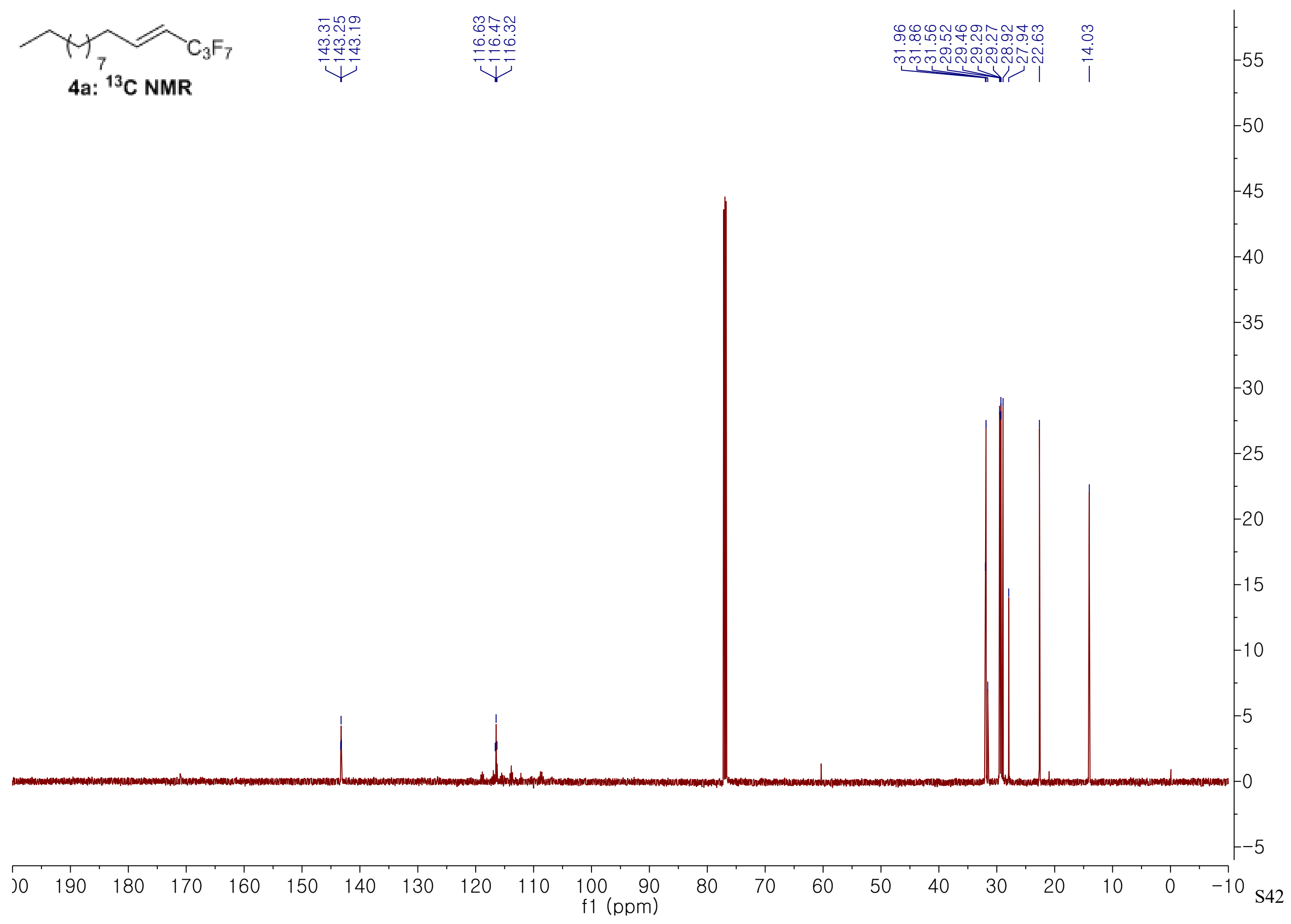


$\widehat{H_{7}} \mathrm{C}_{\mathrm{C}_{3} \mathrm{~F}_{7}}$

4a : ${ }^{19} \mathrm{~F}$ NMR

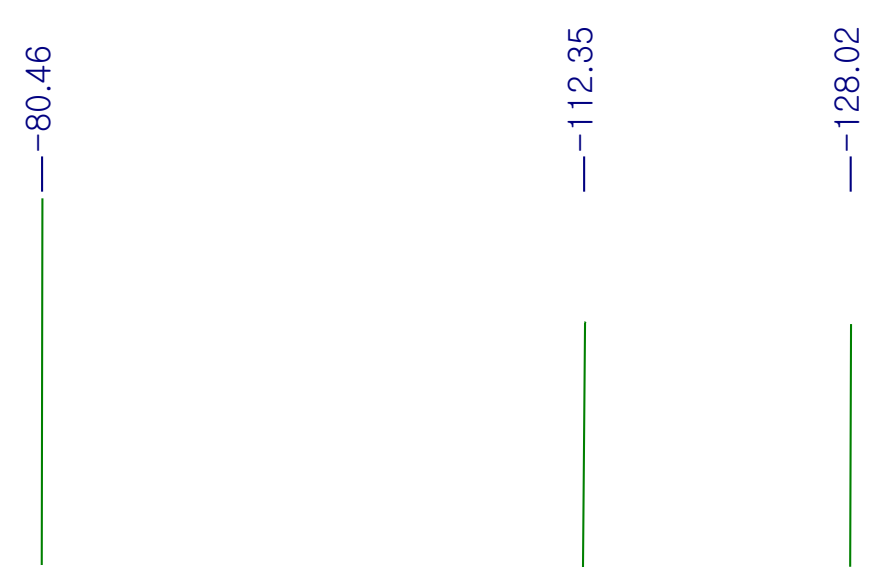

19000

$-18000$

$-17000$

$-16000$

$-15000$

$-14000$

$-13000$

$-12000$

$-11000$

$-10000$

$-9000$

$-8000$

$-7000$

$-6000$

$-5000$

$-4000$

$-3000$

$-2000$

$-1000$

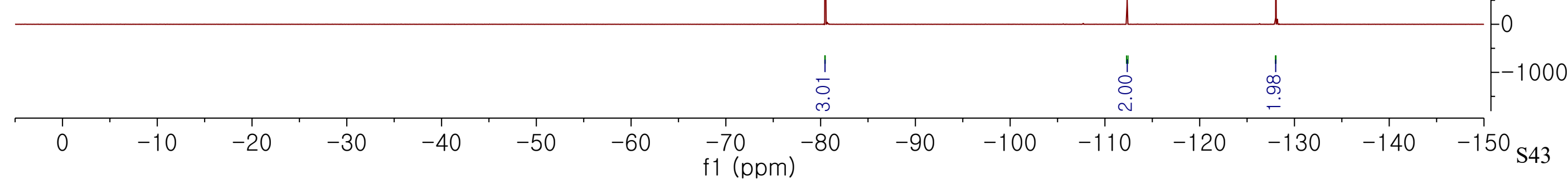


$\widehat{\mathrm{H}_{7}} \mathrm{C}_{\mathrm{C}_{4} \mathrm{~F}_{9}}$

\section{5a : ${ }^{1}$ H NMR}

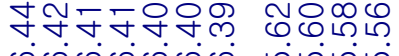

ن

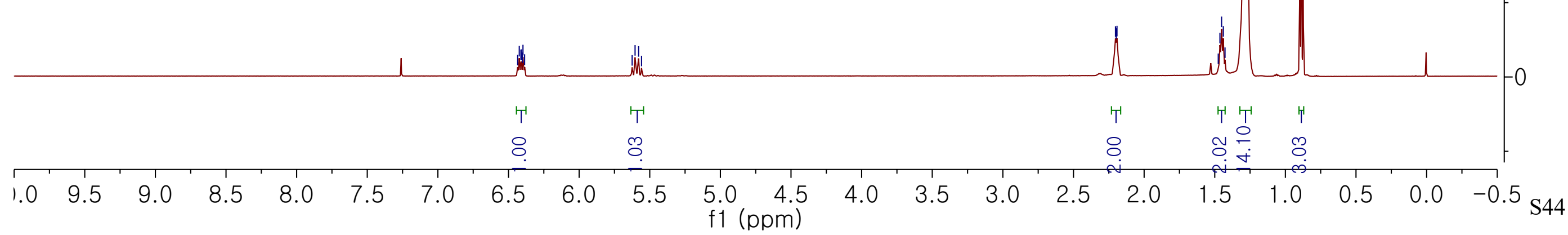




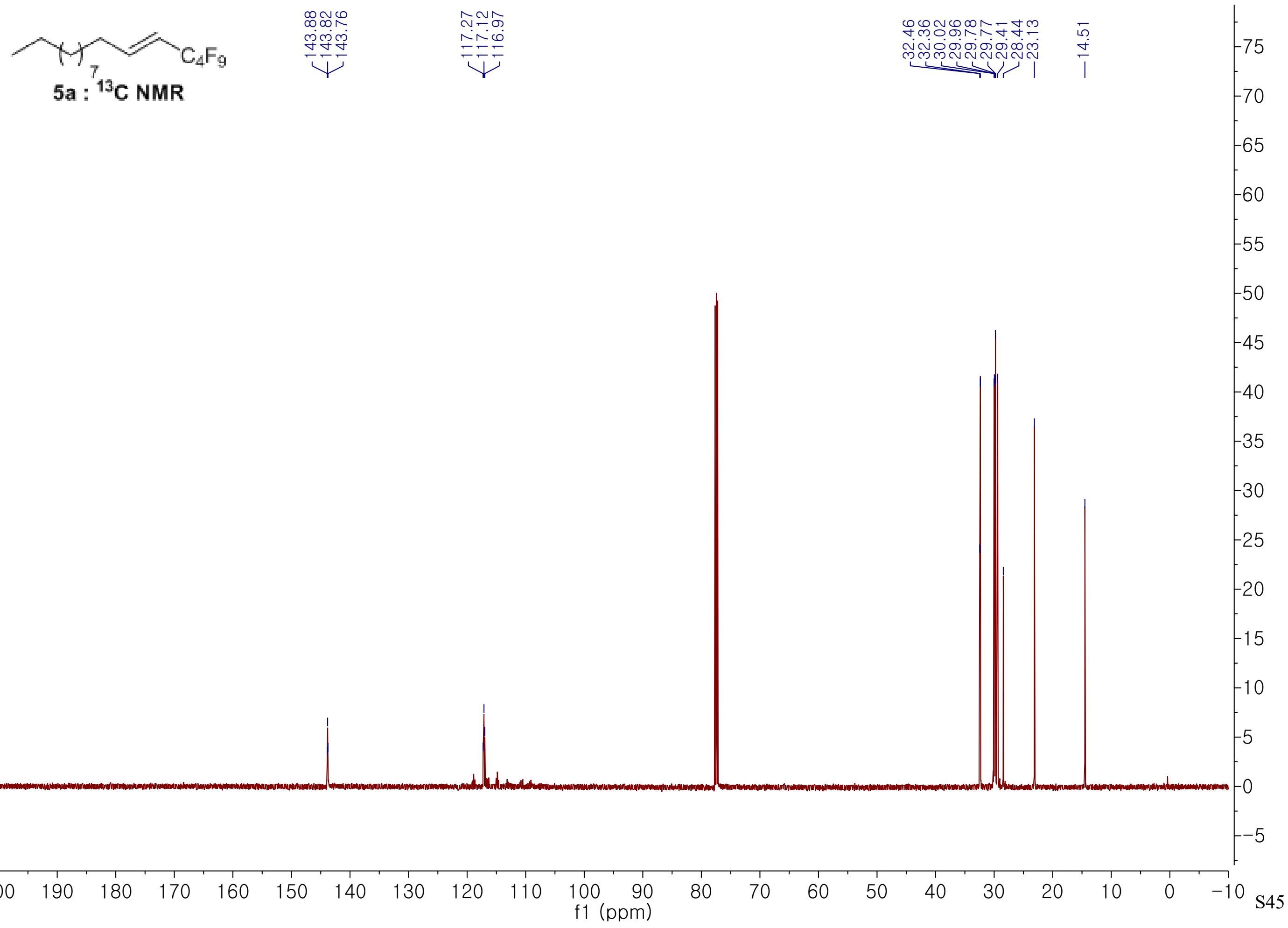




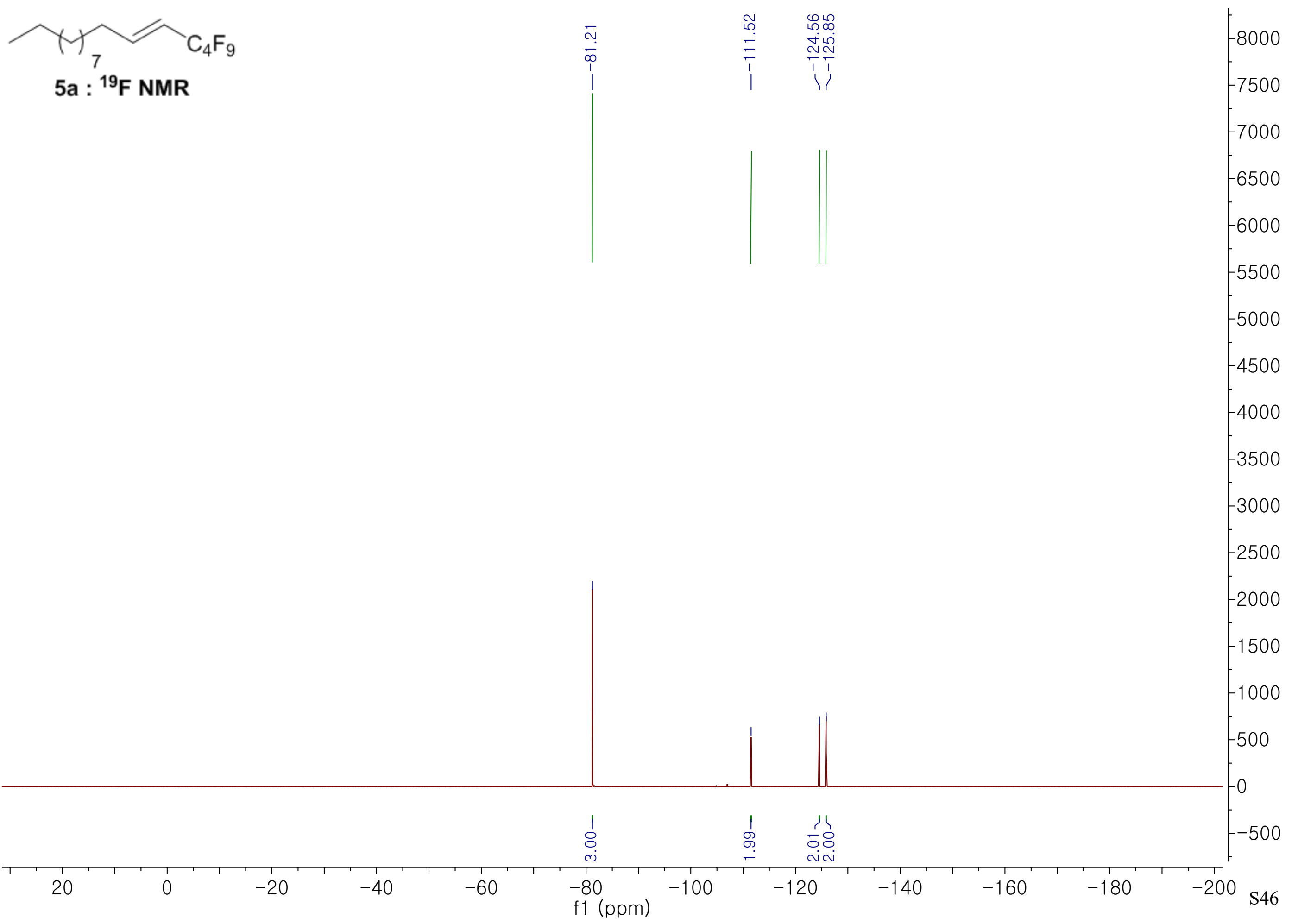



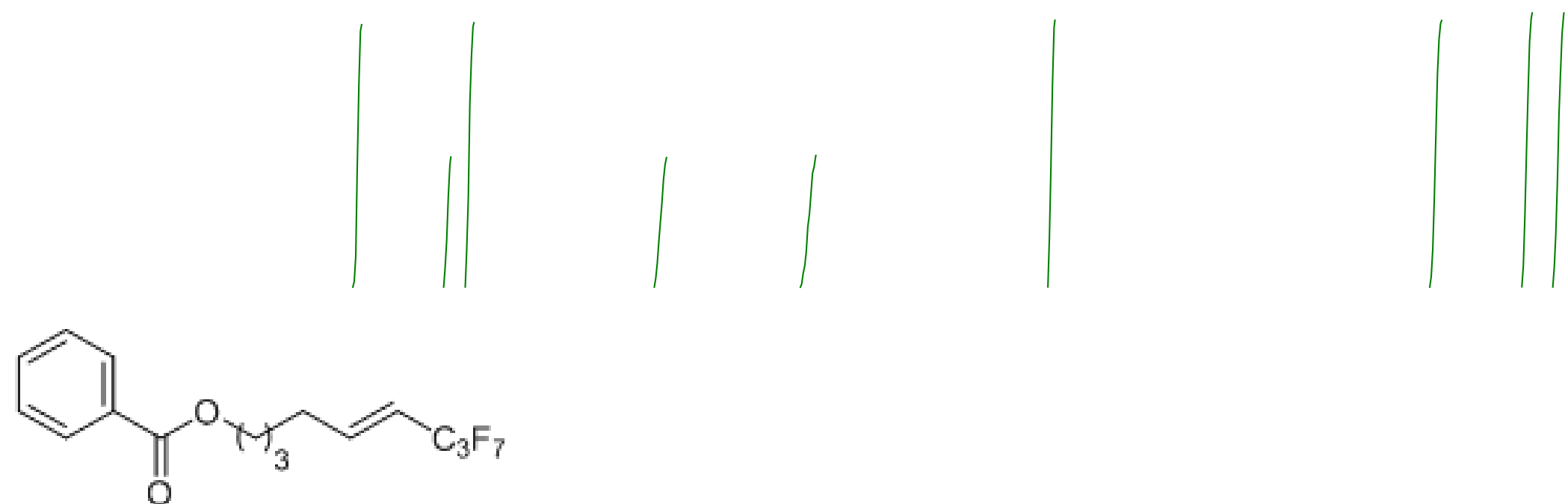

4c: ${ }^{1} \mathrm{H}$ NMR

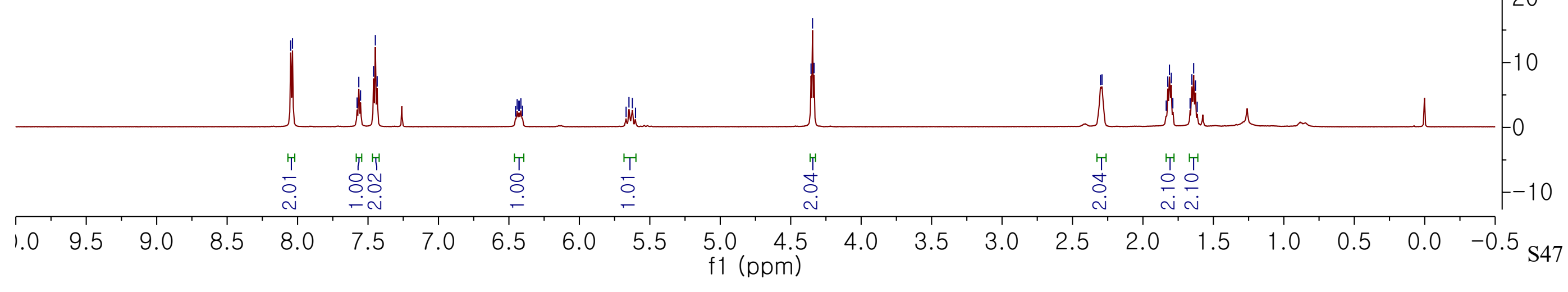




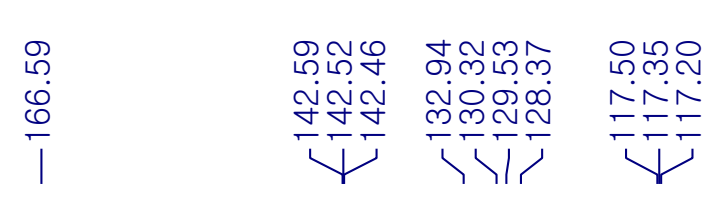

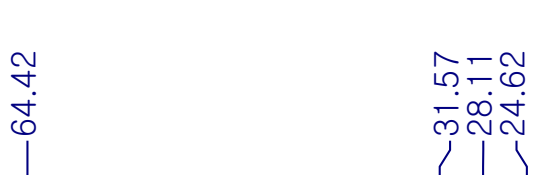

$-210$

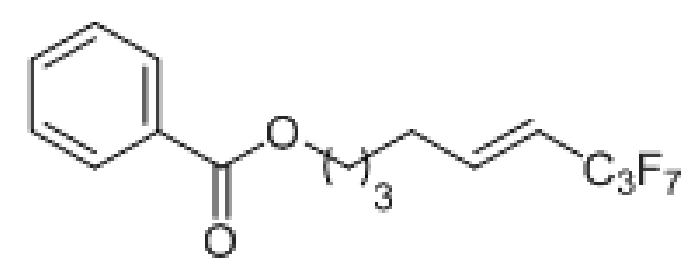

4c: ${ }^{13} \mathrm{C}$ NMR

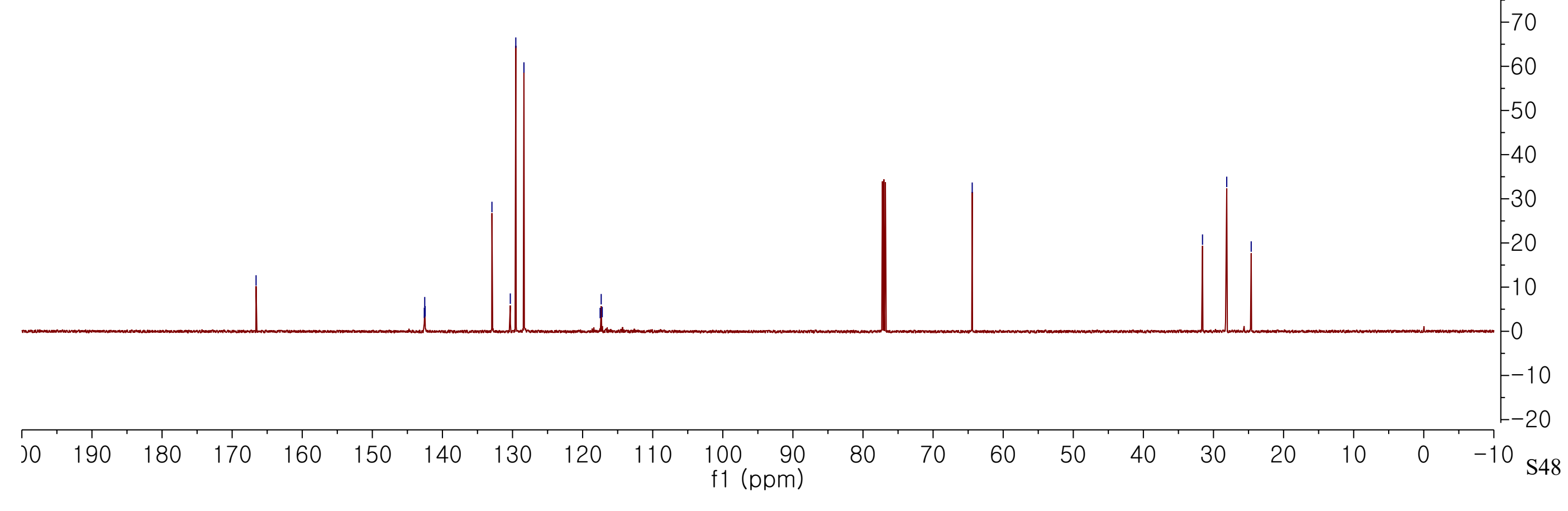




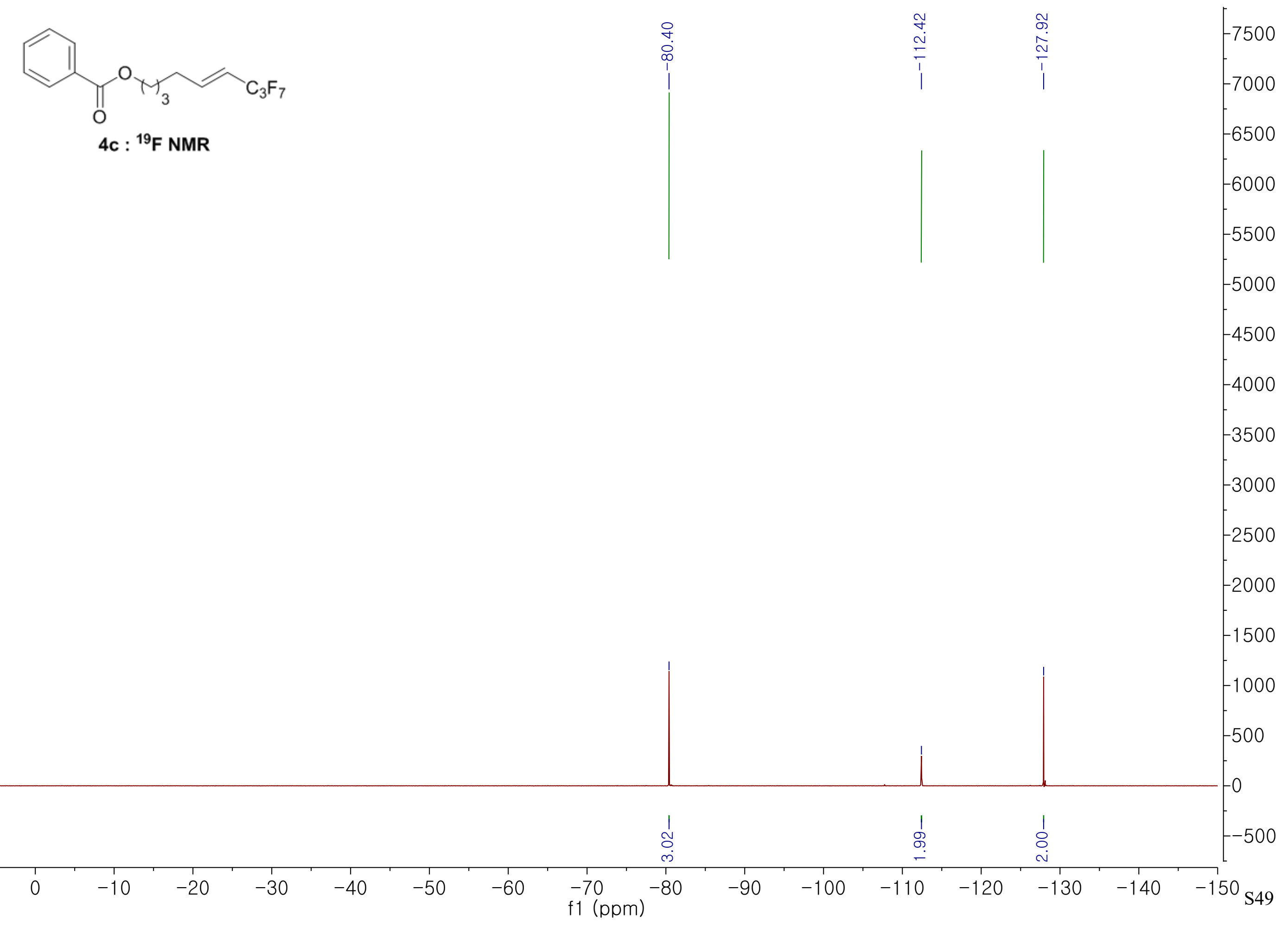



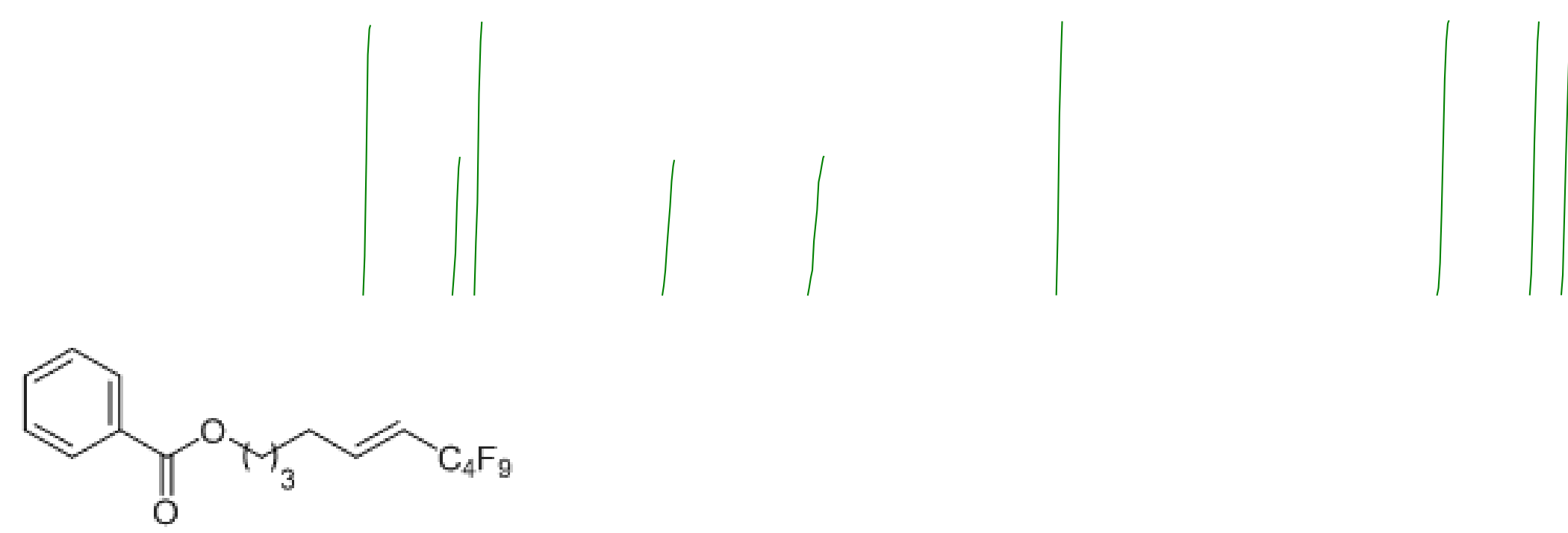

5c: ${ }^{1} \mathrm{H}$ NMR

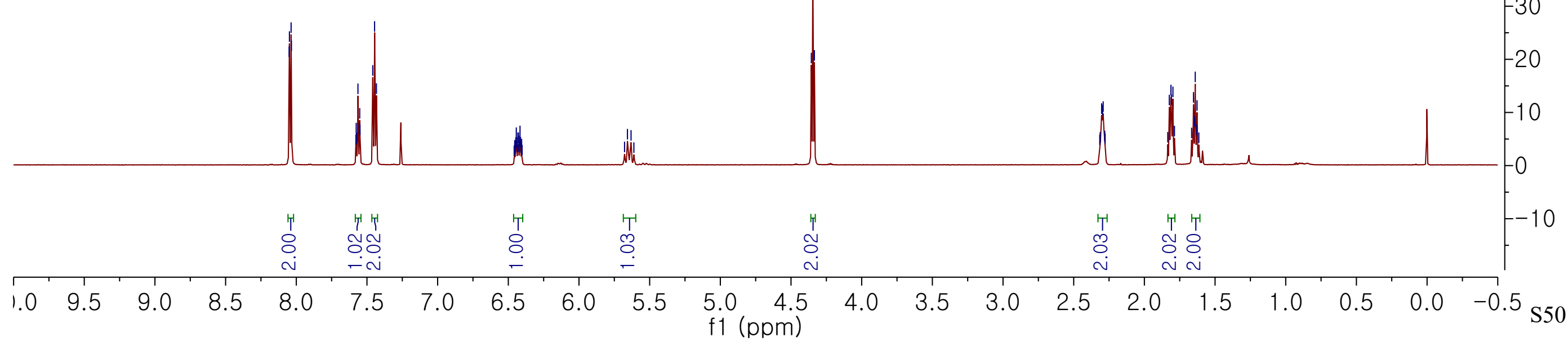




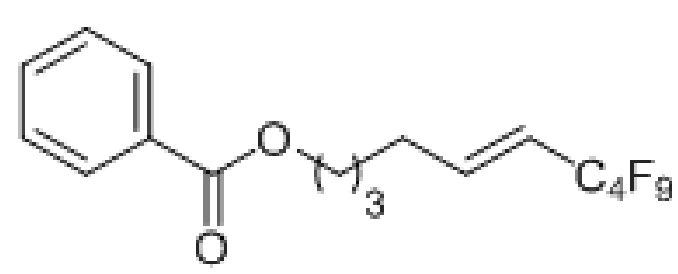

5c: ${ }^{13} \mathrm{C}$ NMR

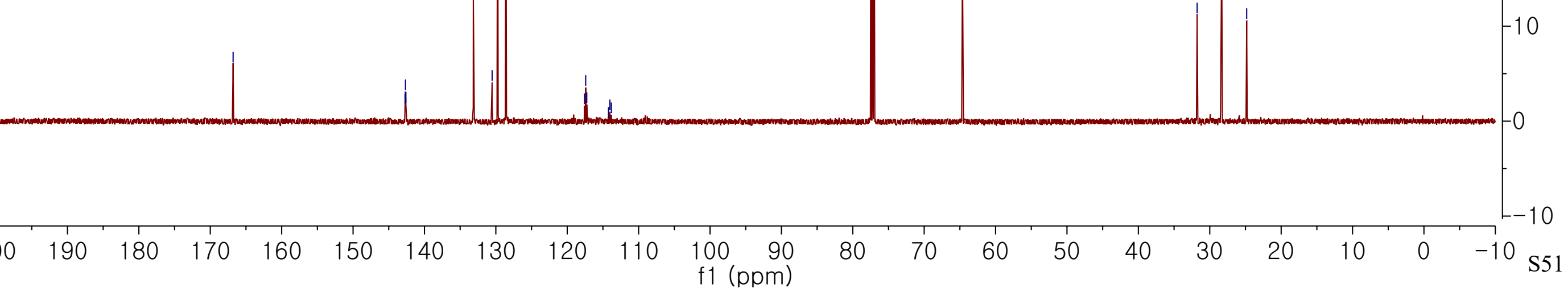




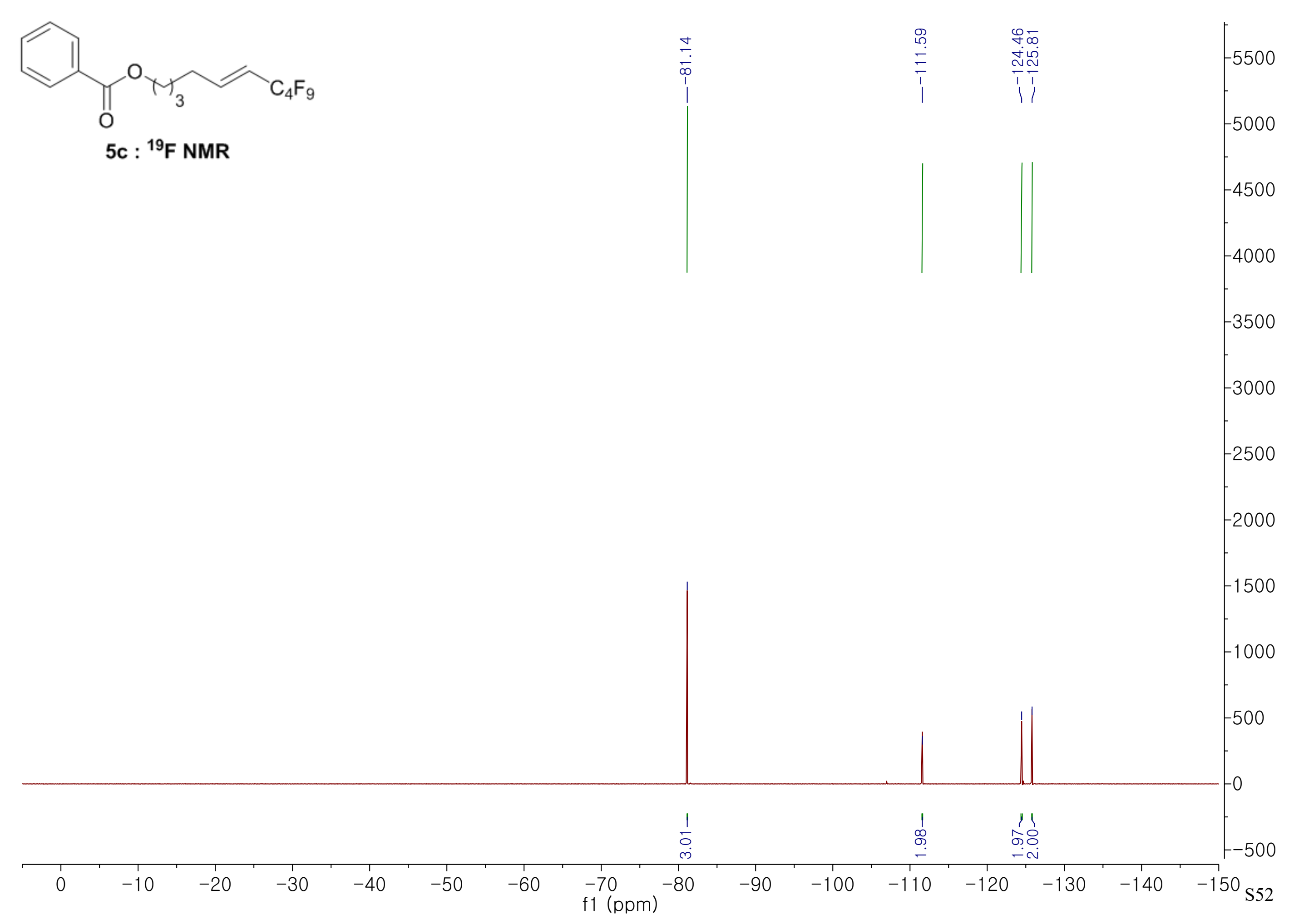



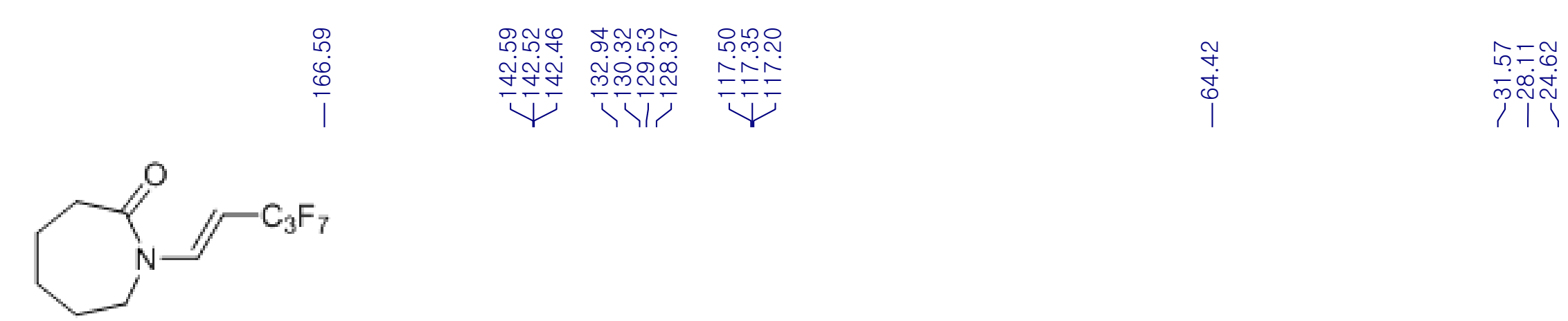

$-210$

4j: ${ }^{13} \mathrm{C}$ NMR

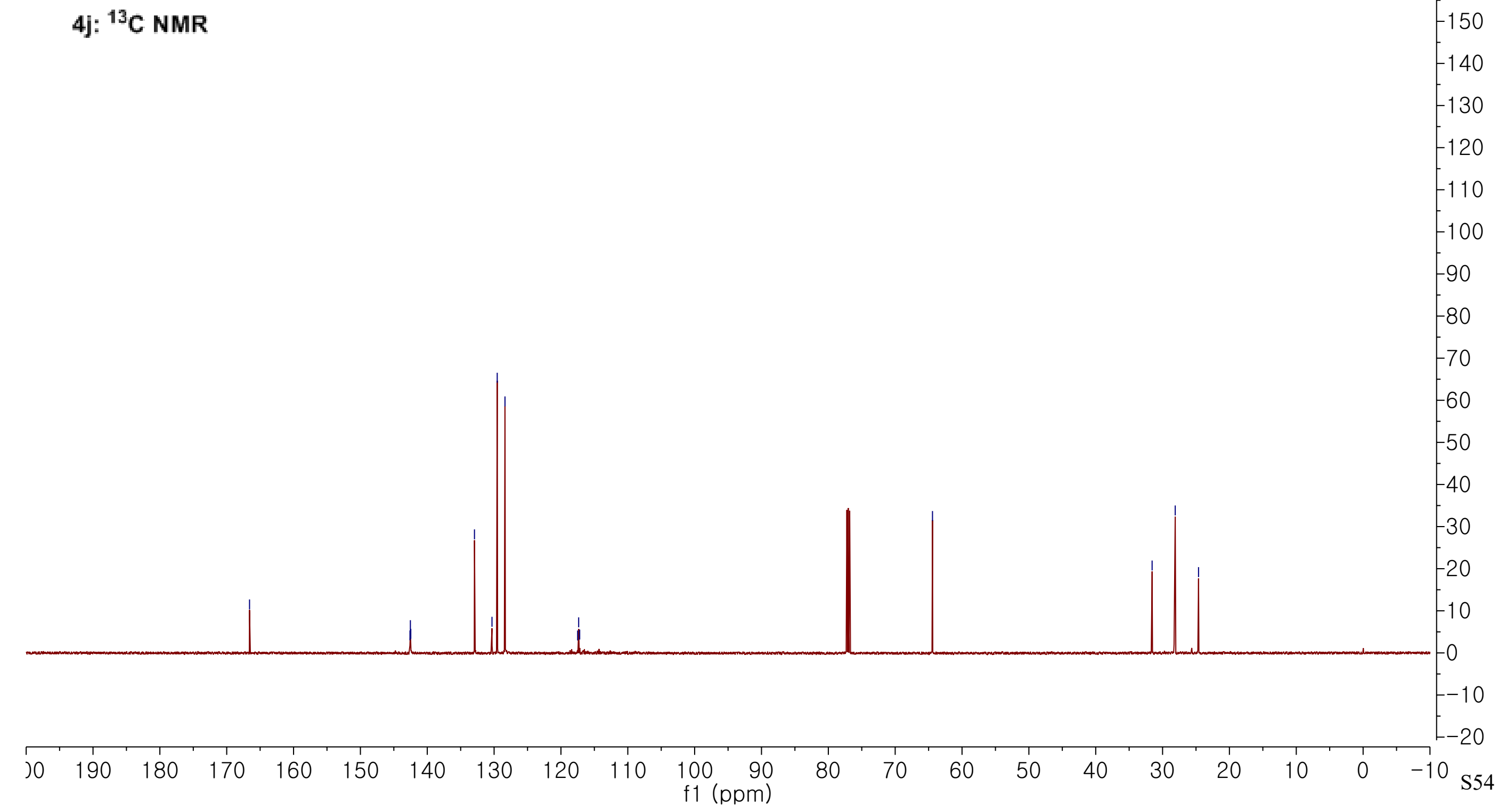



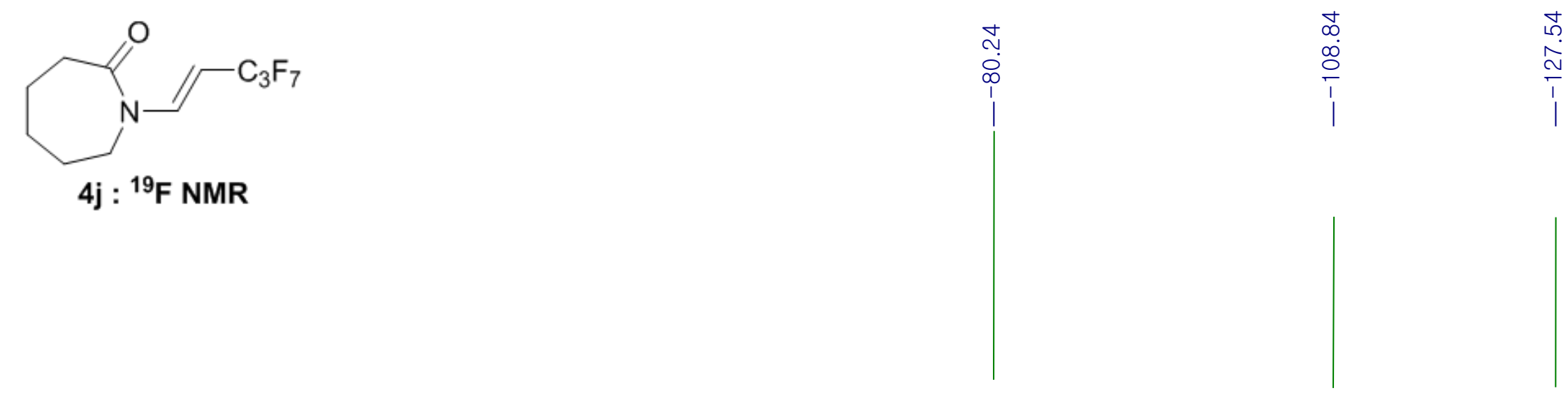

$-4500$

4j : ${ }^{19}$ F NMR

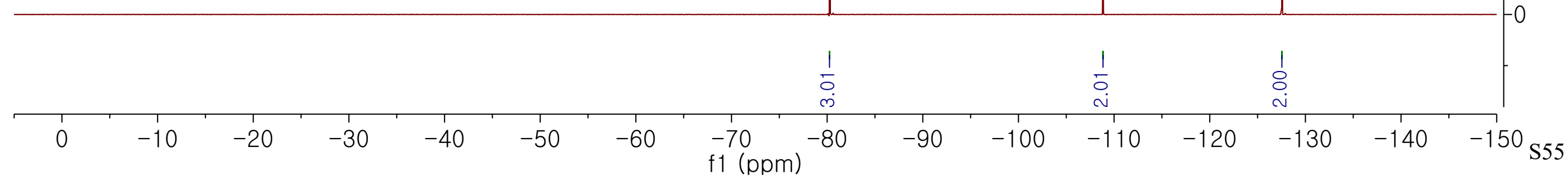




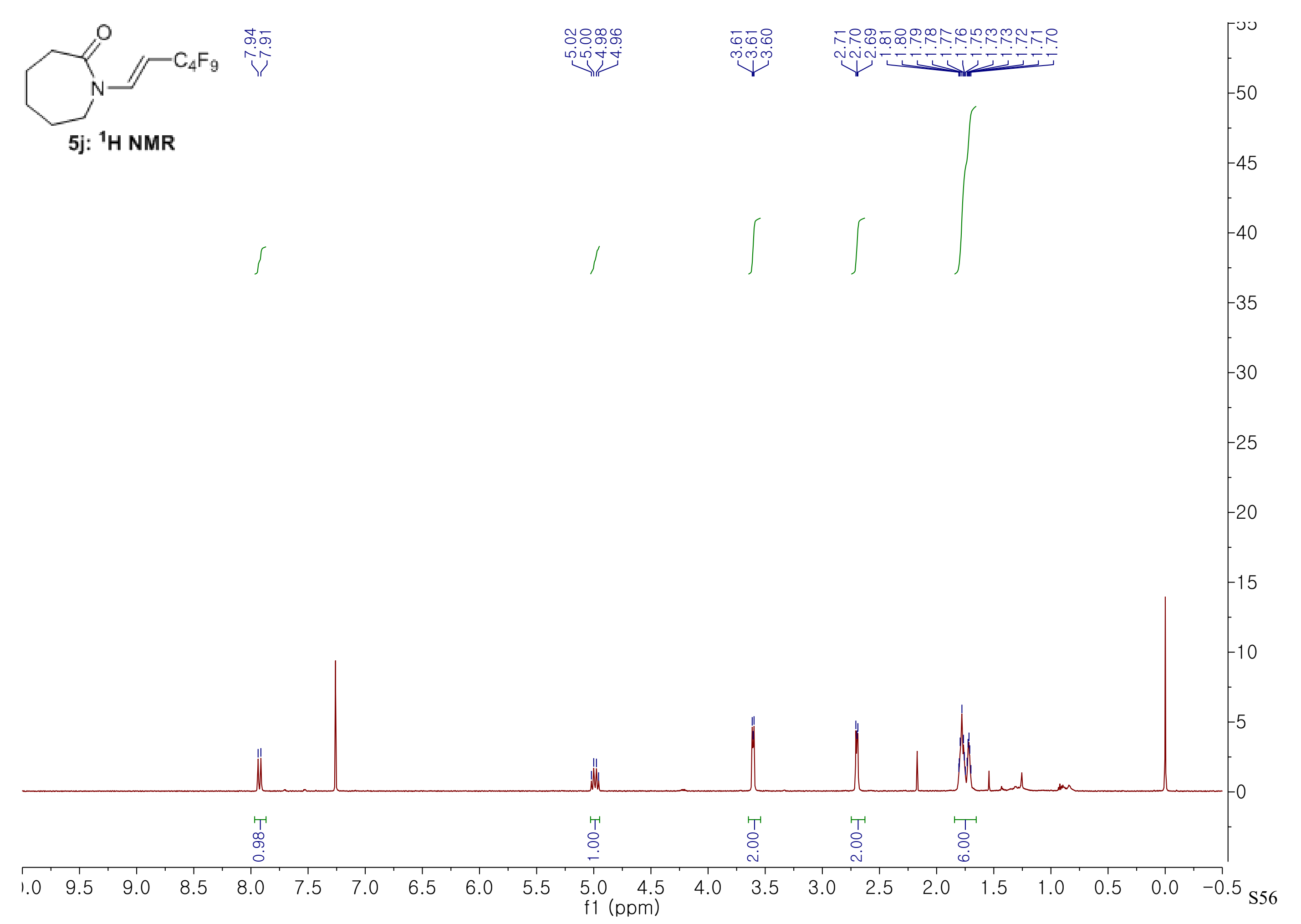



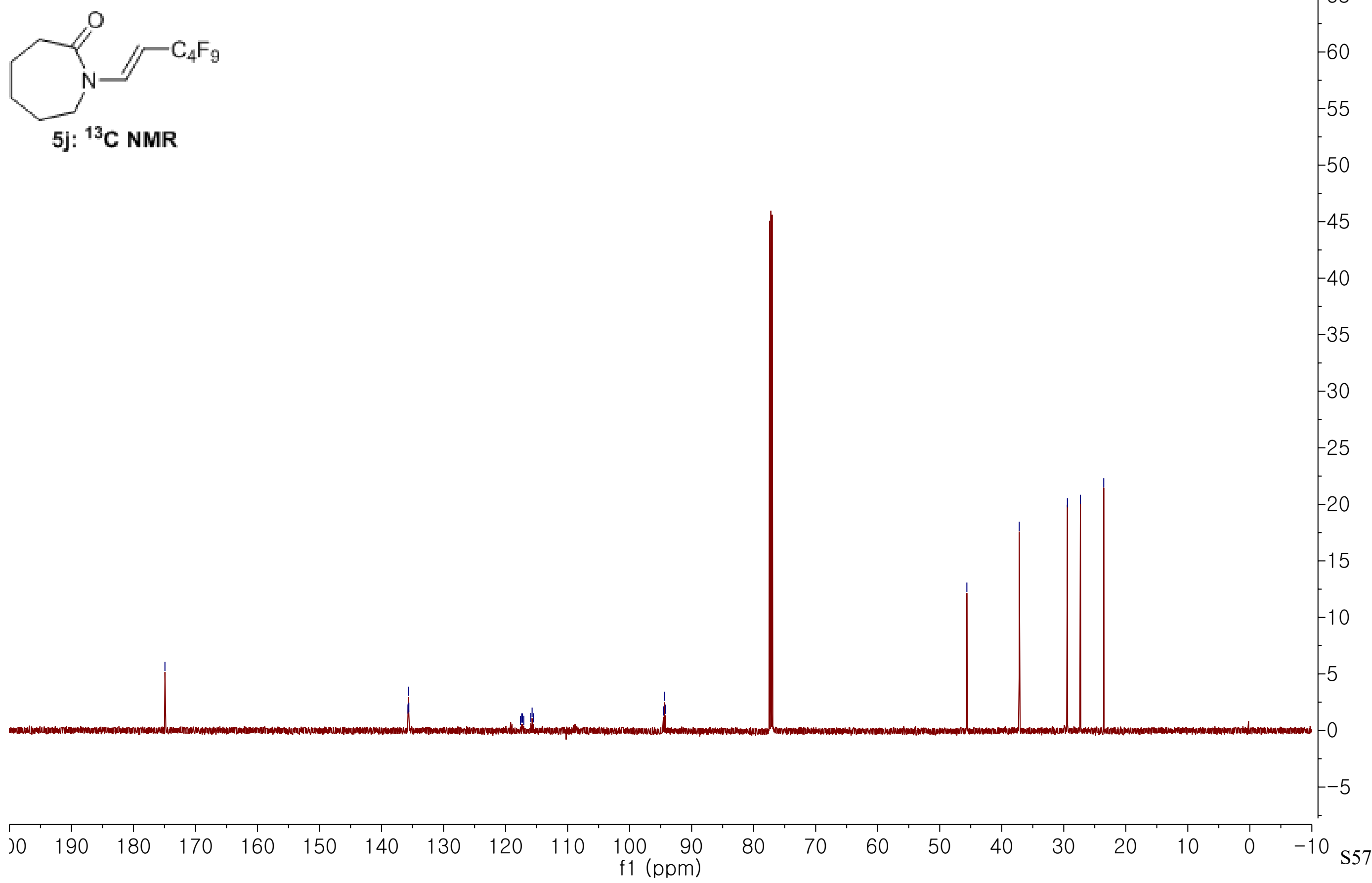


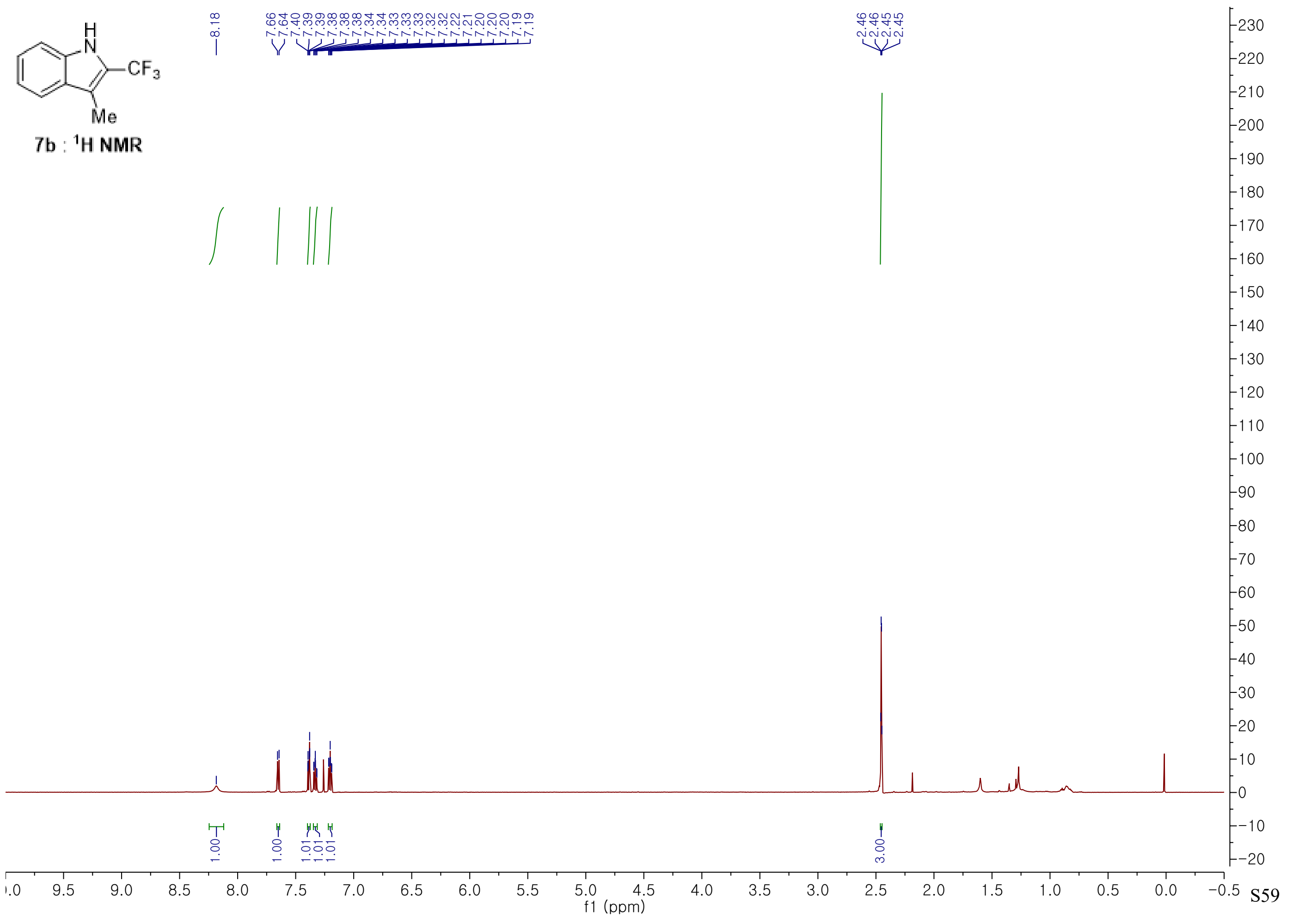




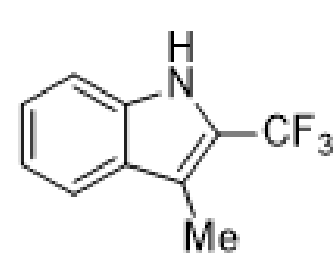

7b: ${ }^{13} \mathrm{C}$ NMR

$\begin{array}{lllll}180 & 170 & 160 & 150\end{array}$

$140 \quad 130$




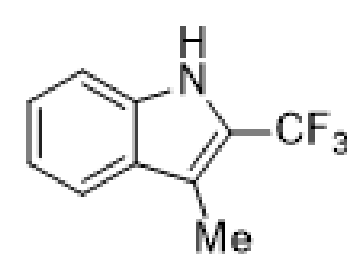

7b: ${ }^{19}$ F NMR

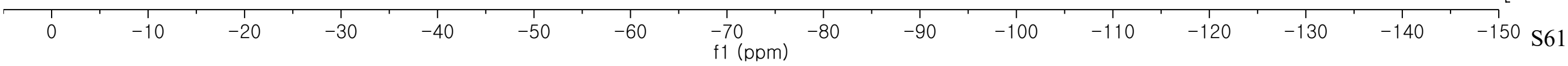

